\title{
Majority Members Misperceive Even "Win-Win” Diversity Policies as Unbeneficial to
}

\section{Them}

\author{
N. Derek Brown \\ Drew S. Jacoby-Senghor \\ University of California, Berkeley
}

In press at the Journal of Personality and Social Psychology (C) 2021, American Psychological Association. This paper is not the copy of record and may not exactly replicate the final, authoritative version of the article. Please do not copy or cite without authors' permission. The final article will be available, upon publication, via its DOI: 10.1037/pspi0000372

\section{Please cite using the following reference:}

Brown, N. D., \& Jacoby-Senghor, D. S. (2021). Majority members misperceive even "win-win" diversity policies as unbeneficial to them. Journal of Personality and Social Psychology. Advance online publication. https://doi.org/10.1037/pspi0000372 


\section{Author Notes}

This research was supported by the Center for Equity, Gender, and Leadership at UC Berkeley's Haas School of Business. We thank Laura J. Kray, Dana R. Carney, Jennifer A. Chatman, Andreana Kendrick, and Don A. Moore for thoughtful feedback on early drafts of this manuscript. We also thank members of the DJS Lab, particularly Isaac Raymundo, Brianna Blair, Madeline Kushner, and Winson Truong, for their invaluable support with this research. Correspondence concerning this article should be addressed to N. Derek Brown, Haas School of Business, University of California, Berkeley, 2220 Piedmont Avenue, Berkeley, CA 94720. E-mail: d_brown@berkeley.edu

$\underline{\text { Online Supplemental Materials }}$

Online Supplemental Tables 


\begin{abstract}
Six studies show that majority members misperceive diversity policies as unbeneficial to their ingroup, even when policies benefit them. Majority members perceived non-zero-sum university admission policies - policies that increase the acceptance of both URM (i.e., underrepresented minority) and non-URM applicants — as harmful to their ingroup when merely framed as “diversity" policies. Even for policies lacking a diversity framing (i.e., "leadership" policies), majority members misperceived that their ingroup would not benefit when policies provided relatively greater benefit to URMs, but not when they provided relatively greater benefit to nonURMs. No consistent evidence emerged that these effects were driven by ideological factors: Majority members' misperceptions occurred even when accounting for self-reported beliefs around diversity, hierarchy, race, and politics. Instead, we find that majority group membership itself predicts misperceptions, such that both Black and White participants accurately perceive non-zero-sum diversity policies as also benefiting the majority when participants are represented as members of the minority group.
\end{abstract}

Keywords: diversity, representation, intergroup dynamics, zero-sum, inequality 


\section{Majority members misperceive even 'win-win' diversity policies as unbeneficial to them}

Even as positive sentiment regarding diversity policies has become more ubiquitous (Bell \& Hartmann, 2007; Fingerhut, 2018), the enactment of effectual policy has often faced backlash from majority group members. Most Americans report valuing diverse organizations (Horowitz, 2019), an increasingly diverse U.S. society (Budiman, 2020), and gender and racial equality (Minkin, 2020; Parker et al., 2020). And yet, initiatives meant to increase the representation of historically underrepresented groups within institutions are frequently construed as harmful and discriminatory to majority group members - particularly to White and Asian Americans (Gershgorn, 2019; Wakabayashi, 2017). Likewise, White and Asian Americans have initiated legal challenges against university affirmative action policies on the basis that such admissions processes are discriminatory towards their racial group (Kramer, 2019). We investigate whether this contradiction between ideological support for but backlash against diversity policies is due in part to majority group membership itself.

In the current research, we hypothesize that majority group members evaluate diversity policies in relative terms, focusing on the intended benefits for minority versus majority group members. Specifically, we predict that majority group members will tend to perceive diversity policies as unbeneficial to their group, even when policies are specifically designed to confer benefits to both majority and minority members (i.e., "win-win" diversity policies). We furthermore predict that this effect largely occurs orthogonally to the influence of majority members' ideological beliefs regarding diversity policies. In making this prediction, we do not dismiss the importance of ideological beliefs in shaping attitudes and behavior. On the contrary, we expect ideologies (e.g., social dominance, explicit prejudice, system justifying beliefs) to predict majority group members' perceptions of diversity policies. Nevertheless, we posit that, 
regardless of these ideological factors, majority group members will perceive policies as less beneficial to the ingroup when policies have been designed to increase the representation of minority groups.

\section{Ideological Beliefs and Diversity Perceptions}

Ideological beliefs are a set of shared beliefs individuals use to interpret their environment (Parsons, 1951). Once established, these beliefs shape individuals' social motivations and influence how people perceive the world (Jost et al., 2004; Kay \& Brandt, 2016; Sidanius \& Pratto, 2001). Myriad ideologies have been identified as shaping perceptions of diversity and diversity policies (Rattan \& Ambady, 2013), including political conservatism, beliefs that diversity does more harm than good, preference for hierarchy, antipathy towards outgroup members, racial identification, and justification of the status quo (e.g., Chow \& Knowles, 2015; Danbold \& Unzueta, 2020; Eibach \& Keegan, 2006; Kraus et al., 2017; Lowery et al., 2006; 2007; Major \& Kaiser, 2017; Verkuyten, 2005; Wilkins \& Kaiser, 2014; Wolsko et al., 2006). For example, individuals high in social dominance orientation express greater opposition to allocating resources in ways that would make majority and minority group outcomes more equal (Federico \& Sidanius, 2002; Sidanius et al., 1994; cf. Ho \& Unzueta, 2015). Anti-Black ideologies similarly predict greater opposition to race-based diversity policies (Harrison et al., 2006; Lowery et al., 2006) and endorsement of beliefs that White people are disadvantaged by such policies (James et al., 2001; Shteynberg et al., 2011). In light of this extensive evidence, we expect more intensely anti-egalitarian, anti-diversity, or anti-outgroup ideologies to correlate with more negative perceptions of diversity policies.

Despite strong evidence for this relationship, however, anti-egalitarian ideologies may not fully explain intergroup disparities. Psychologists have theorized that majority group 
members often exhibit "racism with a smile" (Kunstman et al., 2016; Mendes \& Koslov, 2013), or hold strong racial biases that underlie even earnestly held egalitarian beliefs (Dovidio \& Gaertner, 2000). Empirical evidence supports the contention that majority members' stated ideological beliefs do not always determine whether they ultimately embrace diversity initiatives. Although White Americans report increasingly positive views of diversity policies over time (Ballinger \& Crocker, 2020), their ideological beliefs sometimes only weakly predict support of diversity policies (e.g., Gutiérrez \& Unzueta, 2013; Lowery et al., 2006; Shteynberg et al., 2011; Wilkins et al., 2015). For example, Dover and colleagues (2016) found that although White job applicants expressed heightened concern of anti-White bias at companies with pro-diversity messages, their concern was not moderated by prejudice towards minorities, ethnic identification, or system justifying beliefs. Moreover, White individuals' opposition to allocating resources to the outgroup often occurs irrespective of their stated ideological beliefs (Balliet et al., 2018; cf. Wetherell et al., 2013). Therefore, although White Americans may oppose diversity policies on ideological grounds, White Americans who value diversity, equality, and racial progress may also oppose such policies.

\section{Effect of Majority Group Membership on Diversity Perceptions}

Being a member of an advantaged group may itself lead to more negative perceptions of diversity policies. Two different lines of work suggest why this might be the case. Research has long demonstrated that individuals fundamentally view the world through the lens of their group membership. Social identity and self-categorization theories argue that people classify themselves and others into different social categories (Turner et al., 1987), identifying similar others as ingroup members and dissimilar others as outgroup members (e.g., Castano et al., 2002; Perdue et al., 1990; Tajfel \& Turner, 1979). As a consequence of this categorization process, 
people are more empathic toward ingroup members (Cikara et al., 2014), give ingroup members more financial resources (Ben-Ner et al., 2009; Fershtman \& Gneezy, 2001; Rubin et al., 2014), and cooperate more with ingroup members (Balliet et al., 2014; 2018; cf. Dawes et al., 2007) than outgroup members. The tendency to favor one's ingroup often occurs with little effort and has been shown to operate outside the influence of group-based ideologies (e.g., Fiske \& Neuberg, 1990; Greenwald \& Banaji, 1995; Xiao \& Van Bavel, 2012; Xiao et al., 2016). Therefore, group categorization exerts a unique influence on perceptions.

Research on intergroup hierarchy suggests that belonging to a high-status group also affects how one views the world. In their hierarchical model of intergroup relations, Kteily and Richeson (2016) argue that, in addition to mere group membership, the hierarchical differences between groups fundamentally shape social perceptions. Groups with higher status and power attend to whether their advantaged position in society is undercut or preserved. Prominent studies have shown that majority members report feeling threatened as a result of losing status (Craig \& Richeson, 2014; Danbold \& Huo, 2015), deny the idea of racial and class privilege (Phillips \& Lowery, 2015; 2020), believe their racial group is discriminated against (Norton \& Sommers, 2011), and believe that some groups are superior to others more so than do minorities (Ho et al., 2015; Sidanius \& Pratto, 2001). These tendencies also apply to how majority members perceive diversity policies (Nishii et al., 2018; Unzueta et al., 2012). Majority members tend to oppose initiatives that increase the representation of minorities (e.g., Craig \& Richeson, 2014; Dover et al., 2016; Outten et al., 2012; Plaut et al., 2011) while minority members more consistently support them (Avery, 2003; 2011; Plaut et al., 2009). Majority group membership also predicts how ideal levels of diversity are defined. For instance, White Americans tend to perceive groups as sufficiently diverse when their ingroup remains the numerical majority (Danbold \& Unzueta, 
2020). Thus, majority group members may be more likely than minority group members to perceive diversity efforts as unbeneficial to the majority group. Specifically, we posit thatabove and beyond their stated ideology—majority group members will view a diversity policy's effect in terms of its relative benefits to the ingroup versus the outgroup.

\section{Focus on Relative Outcomes}

Research suggests that people readily compare themselves to others to assess how welloff they are (Festinger, 1954). As a result, people often exhibit a "fixed pie bias" (Thompson \& Hastie, 1990), whereby resource allocation is automatically assumed to be zero-sum (Meegan, 2010; Różycka-Tran et al., 2015), even in situations where all people involved can actually be made better off (Kern et al., 2020; Harinck et al., 2000). For instance, negotiators often assume one side must win and the other must lose, leading them to miss out on mutually beneficial outcomes (Bazerman, 1983; Pinkley et al., 1995; Thompson \& Hastie, 1990). People also assume that everyday transactions — such as buying food or purchasing a vehicle-function in a zerosum manner, leaving one person or group better off than the other (Johnson et al., 2020). Essentially, receiving less than someone else can feel like incurring a loss, even in situations where no one is worse off than before.

The tendency of individuals to focus on relative outcomes is well-reflected in intergroup research. People pay close attention to how the standing of the ingroup compares to that of the outgroup and behave in ways that provide their own group a relative advantage (e.g., Festinger, 1954; Moscatelli et al., 2014; Pratto et al., 1994; Tajfel, 1970; Tajfel \& Turner, 1979). In formative work on the subject, Tajfel and colleagues (1971) showed that people chose to maximize resources allocated to ingroup members relative to outgroup members across a series of tasks. Members of advantaged groups, in particular, perceive improved outcomes for 
disadvantaged groups as leading to worse outcomes for their ingroup (Leach et al., 2002; Smith et al., 2012; Wilkins \& Kaiser, 2014). For example, White individuals' concern for their racial ingroup predicts opposition to affirmative action (Lowery et al., 2006; 2012) and displeasure with increasing demographic diversity (e.g., Craig \& Richeson, 2014; Esses et al., 1998; 2001; see Craig et al., 2018 for a review). Even progress toward equality that does not involve resource allocation is often perceived as involving costs to the advantaged group. For example, White Americans report that as anti-Black bias has decreased over time, anti-White bias has correspondingly increased (Norton \& Sommers, 2011). Across such examples, majority group members perceive benefits to minorities as an indication that their group might be harmed (Wilkins et al., 2015; cf. Earle \& Hodson, 2020).

It is often unclear in this research whether perceptions of harm are at all inaccurate. Many studies have focused on contexts that indeed involve zero-sum outcomes, meaning that perceptions of harm may be partly justified. For example, numerous studies utilize hiring paradigms in which one candidate is selected to the exclusion of another (e.g., Castilla \& Bernard, 2010; Dover et al., 2016; Hekman et al., 2017). Lowery and colleagues (2012) investigated perceptions of group disparities explicitly "when the situation is zero-sum” (p. 328). Similarly, Craig and Richeson (2014) showed that White participants reported higher group status threat when presented with information that White people would be replaced by racial minorities as the new American majority.

Despite researchers often focusing on zero-sum contexts, diversity policies can be, and often are, non-zero-sum. Diversity has been shown to increase work group performance, spark innovative thinking, and improve the economic development of communities (e.g., Apfelbaum et al., 2014; Dezsö \& Ross, 2012; Eagle et al., 2010; Hofstra et al., 2020; Levine et al., 2014; 
Phillips, 2014; Phillips \& Loyd, 2006), thereby providing benefits enjoyed by majority and minority members alike. Diversity policies can also be designed to provide direct benefits to individual majority group members. For example, policies that allocate resources to minority members can simultaneously allocate additional resources to majority members. In the current work, we exclusively study perceptions of this kind of non-zero-sum policy throughout our studies. Specifically, we investigate policies that increase racial equality in school admissions by increasing the number of students from all backgrounds who are admitted to the institution. In doing so, we are able to examine whether majority group members perceive a diversity policy as unbeneficial to the ingroup even when the policy benefits the majority group.

We predict that majority group members, on average, misperceive diversity policies that benefit both majority and minority groups to be less beneficial to the ingroup than they actually are. We predict this misperception is driven by considering relative benefits; that is, majority group members will evaluate policies based on whether the intended benefit to the minority group is relatively greater than it is to the majority group. We also expect participants' ideological beliefs to predict how positively or negatively they view diversity policies. However, we posit that an advantaged position in the social hierarchy separately leads to more negative perceptions of policies that intend to increase diversity. Therefore, we expect that ideology, by and large, will not explain or moderate the unduly negative perceptions majority members have of policies that benefit minority members more than majority members.

\section{Overview of Studies}

Across six studies, we tested perceptions of how non-zero-sum university diversity policies (i.e., policies that increase the likelihood of admission for applicants of all backgrounds) affect majority group members' chances of being accepted. Study 1a examined whether White 
Americans would misperceive the effect that non-zero-sum diversity policies will have on their racial group. Study $1 \mathrm{~b}$ extended this finding to Asian and White undergraduates currently attending a predominantly Asian and White university. Study 2 tested White Americans' perceptions of diversity policies with varying degrees of benefit to their ingroup relative to the minority outgroup. Study 3 examined the extent to which participants' misperceptions were driven by policy framing versus whether the majority or minority group receives greater benefit from the policy. Study 4 tested whether misperceptions are driven by the absolute size of the benefit to the majority group versus by whether the majority or minority group receives greater benefit from the policy. Across Studies 1-4, we simultaneously tested a long list of participants' self-reported ideological beliefs as causal mechanisms and moderators for the observed effect. In Study 5, we recruited both White and Black participants to test whether misperceptions were specific to majority group members as compared to minority group members. Finally, Study 6 manipulated whether White participants misperceptions depend on whether they are represented as members of the majority or minority group.

Data, syntax, and complete materials for each study have been made available on OSF (https://osf.io/9nyz3/). ${ }^{1}$

\section{Study 1a}

We examined White Americans' perceptions of how non-zero-sum diversity policies affect their racial group. Specifically, we tested whether White Americans misperceive university diversity initiatives that are designed to provide benefits for all students as unbeneficial to White people. We also explored whether participants' misperceptions are evident when controlling for ideological beliefs around race, diversity, hierarchy, and politics.

\footnotetext{
${ }^{1}$ Any design or measurement details that are not reported in this paper can be found in our online materials on OSF.
} 


\section{Method}

We preregistered sample and analysis plan on OSF (https://osf.io/f83zp). ${ }^{2}$

Participants. With no a priori expectation of effect size, we preregistered recruiting a sample size of 200 White (non-Hispanic) U.S. citizens. A sensitivity power analysis indicated that a sample of this size allowed us to detect a minimum effect size of $d=0.23$ with at least 95\% power for a one-sample $t$-test. In total, 201 participants from Amazon's Mechanical Turk (MTurk) completed our study in exchanged for \$1. Most (56.4\%) self-identified as politically liberal. Based on preregistered criteria, we excluded seven participants who incorrectly identified the reading materials topic, four participants who did not identify as White (non-Hispanic), and eight participants who indicated that they did not read the materials in full. The resulting final sample included 181 participants $\left(M_{\text {Age }}=39.5, S D=11.8 ; 50.3 \%\right.$ women $)$.

Procedure. Participants were recruited to a study described as "assessing university initiatives." Participants were asked to evaluate a set of policies that a school was ostensibly considering implementing. This study utilized a 1-cell design. All participants read the same fabricated university press release and then completed a multiple-choice attention check asking them to identify the correct title of the press release. Participants then answered how they thought the initiative would affect White applicants' likelihood of admission to the school, followed by various measures of ideological beliefs and demographic information. At the conclusion of the study, participants were debriefed that the press release they saw was fabricated and that the school was not implementing the policies mentioned.

\section{Materials.}

\footnotetext{
${ }^{2}$ All sample sizes, measures, and analyses in the manuscript were preregistered. For the sake of manuscript clarity, we omitted pre-registered analyses that are not central to the hypotheses presented.
} 
Press release. Participants were shown a press release describing a new "Diversity Leaders Program" aimed at increasing the number of underrepresented minorities (URMs) at the institution through four proposed initiatives. Most crucially, participants were told:

This year, Haas will begin its new Diversity Leaders program. Under this program, we will admit fifty additional full-time MBA (FTMBA) students each year who will be chosen using admissions criteria that place greater consideration on applicants' commitment to diversity, equity, and inclusion in their personal, extracurricular, and professional lives. By focusing on applicants' passion for creating diverse organizations, we should attract a larger number of URMs to our applicant pool and increase the number of students of all backgrounds who will help Haas achieve its goal of creating equityfluent leaders.

This section had three critical components signifying that the policies would increase admission of students of all racial backgrounds. First, by stating that diversity would be improved through an increase in the class size, we made explicit that more students would be admitted than in years past. Second, this initiative was described as using a specific set of admissions criteria separate from the general applicant pool, indicating that admission rates for the standard admissions pool would be unaffected. Third, we stated that "students of all backgrounds" would be considered for the fifty additional slots. Therefore, the likelihood of any given student being accepted into the program was increased, not just those from underrepresented minority groups. Rather than a racial quota system, which is commonly associated with affirmative action policies and criticized as being zero-sum (Plaut, 2011; Unzueta et al., 2008), the diversity policy in this study considered a given applicants' commitment to advancing diversity, equity, and inclusion regardless of their racial background. Because this type of policy does not take the race of the 
applicant into account, it has been deemed permissible in places where affirmative action is illegal (Regents of the University of California v. Bakke, 1978; Rothenberg, 2018). In aggregate, these designs assured that the acceptance rate of White applicants should improve upon implementation of the policy. ${ }^{3}$

Following the description of this focal policy were three other proposed initiatives, which were all described using similar non-zero-sum phrasing. Each initiative-funding scholarships for Diversity Leaders, minority-focused recruitment days, and a diversity and inclusion course requirement - was accessible to students of all backgrounds and funded by new donor gifts for the specific purpose of the diversity initiatives. Each policy was deliberately described as improving the outcomes of URM students without negatively affecting the likelihood that other groups would be accepted to the institution.

\section{Measures.}

Perceived ingroup outcome. Participants responded to an item adapted from Lowery and colleagues (2006): “How would the proposed initiatives affect White applicants' chances of getting accepted into Haas?" Participants answered using a 7-point Likert-scale with meaningful anchors: 1 (greatly harm), 4 (no effect), and 7 (greatly improve). For clarity of presentation, we recoded the scale to -3 (greatly harm), 0 (no effect), +3 (greatly improve). Answers below the midpoint therefore indicated the belief that the policies would make White applicants less likely

\footnotetext{
${ }^{3}$ To further inform this assertion, we determined how participants believed the policy would affect the number of White applicants to the school. Pilot study participants $(N=48)$ viewed the Study 1 stimuli and answered the following question (Kraus et al., 2017): "For every 100 White applicants that applied to Haas before this initiative, how many White applicants do you think will apply to Haas after this initiative goes into effect. (100 would mean the number of White applicants will not change.)" Participants reported that roughly $14 \%$ fewer White people would apply to the school after the policy begins, $M=85.6, S D=29.73, t(47)=-3.34, p=.002,95 \%$ CI [77.0, 94.3], indicating that the increased class size described in the stimuli should indeed be perceived as increasing applicants' chances of admission.
} 
to be accepted into the school whereas answers above the midpoint indicated the belief that White applicants would be more likely to be accepted into the school.

Importantly, the Diversity Leaders program described above mathematically increases the odds of any applicant being admitted. To the extent that participants accurately acknowledge that White people can benefit from this program, ratings on this measure should be significantly above the scale midpoint. If participants interpreted the new policy as solely benefiting URM students, the odds of a White applicant being accepted to the school would remain unchanged and ratings on this measure should not significantly differ from the midpoint (i.e., no effect). Finally, ratings significantly lower than the midpoint on this perceived ingroup outcome measure would indicate that participants incorrectly conclude - and thus misperceive - that the policy harms White applicants' likelihood of being admitted.

Ideological beliefs. We measured an array of ideological beliefs to use as covariates. In prior research, these measures have been shown to predict perceptions of diversity policies and intergroup attitudes. We presented ideological measures in randomized order.

Anti-diversity policy beliefs. We created a 4-item measure assessing anti-diversity policy beliefs $(\alpha=.92)$ : "Policies meant to benefit racial minorities do more harm than good," "Policies meant to benefit racial minorities are unfair to White people," "Policies supporting diversity are necessary for organizations to be successful" (reverse-scored), "Policies supporting diversity cause White people to be replaced by members of minority ethnic groups"; 1 (strongly disagree) to 7 (strongly agree).

Political orientation. Three items asked participants to indicate their social, economic, and overall political views on a 4-point Likert scale $(\alpha=.94) ; 1$ (very liberal) to 4 (very conservative). 
Social dominance orientation. The 4-item scale (SDO) assessed participants' endorsement of hierarchy between groups ( $\alpha=.89$; Kteily et al., 2011): "It's probably a good thing that certain groups are at the top and other groups are at the bottom," "Inferior groups should stay in their place," "We should do what we can to equalize conditions for different groups" (reverse-scored), "We should increase social equality" (reverse-scored); 1 (strongly oppose) to 7 (strongly favor).

Modern Racism. The 6-item scale (MRS) measured explicit prejudice towards Black people ( $\alpha=.91$; McConahay, 1986): "Over the past few years, the government and news media have shown more respect to Black people than they deserve," "It is easy to understand the anger of Black people in America" (reverse-scored), "Discrimination against Black people is no longer a problem in the United States," "Over the past few years, Black people have gotten more economically than they deserve," "Black people are getting too demanding in their push for equal rights," "Black people should not push themselves where they are not wanted"; 1 (strongly disagree) to 7 (strongly agree).

Global zero-sum beliefs. A 4-item scale assessed general beliefs about whether groups' outcomes are zero-sum ( $\alpha=.90$; Wilkins et al., 2015): "When one group gets ahead, the others are held back," "Progress for one group does not have to come at the expense of another" (reverse-scored), "Gains for one group means another group loses," "Decreased bias toward one group naturally means another group will experience more bias"; 1 (strongly disagree) to 7 (strongly agree).

Endorsement of colorblind ideology. A 4-item scale assessed participants' desire to disregard race in decision-making ( $\alpha=.92$; Knowles et al., 2009): "I wish people in this society would stop obsessing so much about race," "People who become preoccupied by race are 
forgetting that we are all just human," "Putting racial labels on people obscures the fact that everyone is a unique individual," "Race is an artificial label that keeps people from thinking freely as individuals"; 1 (strongly disagree) to 7 (strongly agree).

Group status threat. One item used by Craig and Richeson (2014): "If they increase in status, racial minorities are likely to reduce the influence of White Americans in society"; 1 (strongly disagree) to 7 (strongly agree).

Symbolic threat. Two items adapted from Danbold and Huo (2015) assessed perceived differences in the values of one's ingroup compared to outgroups $(\alpha=.83)$ : "The values and beliefs of other ethnic groups are not compatible with the values and beliefs of my ethnic group," "Other ethnic groups are undermining American culture"; 1 (strongly disagree) to 7 (strongly agree).

Prototypicality threat. Two items adapted from Danbold and Huo (2015) assessed the degree to which participants felt their status as a prototypical American was threatened $(\alpha=.57)$ : "I believe that there will always be a place for my ethnic group in American society" (reversescored), "I fear that in 40 years' time, it won't be clear what it means to be an American"; 1 (strongly disagree) to 7 (strongly agree).

Identity centrality. Four items assessed the importance of one's racial identity to their self-concept ( $\alpha=.85$; Luhtanen \& Crocker, 1992): "I often think about my race," "Overall, my race has very little to do with how I feel about myself” (reverse-scored), "My race rarely enters my mind" (reverse-scored), "In general, my race is an important part of my self-image"; 1 (strongly disagree) to 7 (strongly agree).

\section{Results}


Table 1 displays means and standard deviations for variables, and correlations between perceived ingroup outcome and all ideological variables. ${ }^{4}$

Table 1.

Means, SD, and Correlations from Study 1a Variables

\begin{tabular}{lccc}
\hline \multicolumn{1}{c}{ Variable } & $\boldsymbol{M}$ & $\boldsymbol{S D}$ & $\begin{array}{c}\text { Perceived ingroup } \\
\text { outcome }\end{array}$ \\
\hline 1. Political orientation (overall) & 2.30 & 0.83 & $-.38^{* * *}$ \\
2. Political orientation (social) & 2.11 & 0.87 & $-.32^{* * *}$ \\
3. Political orientation (economic) & 2.42 & 0.86 & $-.37 * * *$ \\
4. Social dominance orientation & 2.36 & 1.50 & $-.31^{* * *}$ \\
5. Modern racism & 2.80 & 1.53 & $-.37 * * *$ \\
6. Group status threat & 3.93 & 1.84 & $-.16^{*}$ \\
7. Symbolic threat & 2.75 & 1.75 & $-.30^{* * *}$ \\
8. Prototypicality threat & 2.81 & 1.47 & $-.35^{* * *}$ \\
9. Global zero-sum beliefs & 3.09 & 1.55 & $-.36^{* * *}$ \\
10. Anti-diversity policy beliefs & 3.41 & 1.83 & $-.56^{* * *}$ \\
11. Identity centrality & 2.86 & 1.39 & .012 \\
12. Endorse colorblindness & 5.12 & 1.69 & $-.26^{* * *}$ \\
\hline Note. $N=181 .{ }^{*} p<.05, * * p<.01, * * * p<.001$ & (two-tailed). &
\end{tabular}

As predicted, White participants misperceived the policy's effect on White applicants.

Using the DV scale midpoint as the reference value, a one-sample $t$-test revealed that participants incorrectly believed the proposed initiatives would harm White applicants' likelihood of being accepted into the institution, $M=-0.71, S D=1.17, t(180)=-8.22, p<.001,95 \% \mathrm{CI}[-0.88,-$ $0.54]$.

As preregistered, we next controlled for participants' various ideologies. We entered perceived ingroup outcome as the dependent variable and all mean-centered ideological belief measures as simultaneous predictors in a multiple linear regression model. The intercept

\footnotetext{
${ }^{4}$ See SOM for bivariate correlations between all variables in each study.
} 
statistics provided the focal result. Even controlling for ideological beliefs, participants misperceived that the diversity policies would harm White' likelihood of acceptance, $B=-0.71$, $S E=0.071, t(167)=-10.01, p<.001,95 \%$ CI $[-0.85,-0.57] .^{5}$

\section{Discussion}

Consistent with our hypothesis, White Americans misperceived a diversity policy as harmful to their racial ingroup. Specifically, we described the new policy as increasing the class size and applicable to any student regardless of their racial background. Therefore, even under the least charitable interpretation of the policy — wherein all additional slots would be allotted to non-White applicants - the likelihood of White applicants being accepted into the school would not decrease. Nonetheless, White participants believed that the policy would harm White applicants' likelihood of being accepted.

This effect persisted when controlling for various ideological measures, including, but not limited to, participants' general support for diversity policies, political beliefs, support for hierarchy, explicit prejudice towards Black people, and perceived threat to one's status in American society. Therefore, initial evidence suggests a general tendency among White participants to misperceive how non-zero-sum diversity policies will affect racial ingroup members, rather than backlash only from those who are most ideologically opposed to such policies.

\section{Study $1 b$}

Study $1 \mathrm{~b}$ tested whether the effects from Study 1a hold true when participants have direct involvement and identification with the institution in question. It is possible that actual members of a diversity-valuing university in a heavily liberal area of the U.S. would have different

\footnotetext{
${ }^{5}$ See SOM Table S2 for full reporting of estimated marginal means and $95 \%$ CIs for \pm 1 SD on each ideology measure.
} 
perceptions of diversity policies proposed at their institution compared to White Americans generally. We therefore recruited to the laboratory students of races (i.e., White and Asian Americans) that are not underrepresented (i.e., non-URM) and widely considered to be part of the majority within their university context (Birnbaum et al., 2020). These students then evaluated policies ostensibly proposed by the school they attended. All other elements were identical to Study 1a.

\section{Method}

We preregistered sample and analysis plan on OSF (https://osf.io/xcszu).

Participants. We again aimed to recruit 200 undergraduates, with the goal of obtaining 100 White students and 100 Asian students. This sample size would be large enough to detect the effect size in Study 1a $(d=.61)$ with $100 \%$ power. In total, 183 undergraduate Haas students were recruited to participate in exchange for course credit. ${ }^{6}$ Based on preregistered criteria, we excluded 13 participants who incorrectly answered the first attention check regarding the content of the materials and 30 participants who indicated that they did not read the materials in full. We excluded five participants who did not answer our main dependent variable. The resulting final sample included 135 participants $\left(n=78\right.$ Asian/Asian-American; $M_{A g e}=20.8, S D=1.91,37.0 \%$ women). Most (81.5\%) self-identified as politically liberal.

Procedure, Materials, and Measures. The study design was identical to Study 1a. Each participant indicated how they anticipated the policy would affect their own racial ingroup ('How would the proposed initiatives affect White [Asian] applicants' chances of getting accepted into Haas?") using the same 7-point Likert scale, recoded as -3 (greatly harm), 0 (no effect), and +3 (greatly improve) for presentation. Once again, responses below the midpoint

\footnotetext{
${ }^{6}$ We recruited a lower number of participants than preregistered due to COVID-19 shelter-in-place orders.
} 
indicated belief that the policies would make their racial group less likely to be accepted into the school whereas answers above the midpoint indicated belief that their racial group would be more likely to be accepted.

\section{Results}

Table 2 displays means and standard deviations for variables, and correlations between perceived ingroup outcome and all ideological variables.

Table 2.

Means, SD, and Correlations from Study $1 b$ Variables

\begin{tabular}{lccc}
\hline \multicolumn{1}{c}{ Variable } & $\boldsymbol{M}$ & $\boldsymbol{S D}$ & $\begin{array}{c}\text { Perceived ingroup } \\
\text { outcome }\end{array}$ \\
\hline 1. Political orientation (overall) & 2.09 & 0.59 & -.10 \\
2. Political orientation (social) & 1.88 & 0.66 & $-.20^{*}$ \\
3. Political orientation (economic) & 2.27 & 0.68 & $-.18^{*}$ \\
4. Social dominance orientation & 1.86 & 0.97 & -.09 \\
5. Modern racism & 2.08 & 1.01 & -.03 \\
6. Group status threat & 3.91 & 1.64 & -.06 \\
7. Symbolic threat & 2.32 & 1.15 & $-.22^{* *}$ \\
8. Prototypicality threat & 2.79 & 1.09 & -.01 \\
9. Global zero-sum beliefs & 2.74 & 1.14 & $-.23^{* *}$ \\
10. Anti-diversity policy beliefs & 2.82 & 1.16 & $-.24^{* *}$ \\
11. Identity centrality & 4.20 & 1.37 & .10 \\
12. Endorse colorblindness & 4.34 & 1.57 & -.02 \\
\hline
\end{tabular}

Note. $N=135 . * p<0.05,{ }^{*} p<.01, * * * p<.001$ (two-tailed).

Replicating Study 1a, non-URM (i.e., White and Asian) participants misperceived the policy's effect on their racial ingroup. A one-sample $t$-test with the DV scale midpoint as the reference value revealed that participants believed the proposed initiatives would harm their racial group's likelihood of being accepted, $M=-0.81, S D=1.10, t(134)=-8.56, p<.001,95 \%$ CI $[-0.99,-0.62] .^{7}$

\footnotetext{
${ }^{7}$ The effect remains the same when separately analyzing White $(M=-0.88, S D=0.98, t(56)=-6.74, p<.001 ; 95 \%$ CI $[-1.14,-0.62])$ and Asian $(M=-0.76, S D=1.18, t(77)=-5.68, p<.001 ; 95 \%$ CI [-1.02, -0.49]) participants.
} 
As in Study 1a, this effect held even when controlling for their various ideologies in a multiple linear regression, $B=-0.83, S E=0.087, t(117)=-9.57, p<.001,95 \%$ CI $[-1.01$, $0.66] .^{8}$

\section{Discussion}

Study $1 \mathrm{~b}$ replicated the results of Study 1a with non-URM (i.e., White and Asian) students enrolled at the institution where the policies were ostensibly proposed. This effect again held true even when controlling for participants' ideological beliefs. Furthermore, this sample of students was collected in a university and region of the country that is especially liberal and explicitly values diversity, further suggesting that the effects in Study 1 are not solely due to ideological opposition to such policies.

However, an alternative explanation for the Study 1 findings is that participants may have had difficulty deciphering the effect the policy would have on their ingroup. Our intention for this design was to maximize the ecological validity of our materials and findings. The initiatives detailed in the press release are common approaches universities use to address underrepresentation (i.e., application criteria valuing contributions to diversity, minority-focused job events, scholarship funding, and diversity-related curriculum) and the press release itself was carefully designed to appear identical to actual online press releases from the school. Therefore, participants were required to lend their attention to various details that were not directly related to student acceptance rates before inferring what the effect might be for their racial group. In subsequent study designs, we made relevant acceptance rate information explicit and highly salient.

Additionally, we found no difference between White and Asian students' perceptions of how the policy would affect their group, $t(130.51)=0.65, p=.52,95 \%$ CI $[-0.25,0.49]$.

${ }^{8}$ See SOM Table S4 for full reporting of estimated marginal means (EMMs) and 95\% CIs for \pm 1 SD on each ideology measure. 


\section{Study 2}

We tested whether majority members misperceive non-zero-sum diversity policies as unbeneficial to the ingroup even when the mutual benefits are explicit and obvious. We predicted that participants would again form unduly negative perceptions of the diversity policy's effect even with this clear and direct evidence that all groups would be made better off.

Additionally, we explored whether participants' misperception of the effect on White applicants depended on the proportion of URM and non-URM applicants who benefit from the policy. One possibility is that White participants are primarily attuned to how many additional students of each racial group are being admitted. For example, majority members may focus on whether relatively more URM students, relatively more non-URM students, or equal numbers of each are being added the incoming class. Or they may focus on whether the policy increases or decreases the overall representation of their racial group within the institution. Another possibility is that majority members will misperceive any non-zero-sum diversity policy as harmful to their racial ingroup. Accordingly, we manipulated the number of additional admissions each racial group would receive: +15 URM and +35 non-URM (slightly exacerbating unequal representation overall), +25 of each (slightly reducing unequal representation overall), or +35 URM and +15 non-URM (reducing unequal representation overall). To compare these conditions to Study 1, we also included a control condition in which the exact number of additional admissions of each race was not specified.

\section{Method}

We preregistered sample and analysis plan on OSF (https://osf.io/arn9d)

Participants. We preregistered recruiting a sample size of 400 White (non-Hispanic) U.S. citizens, targeting 100 participants per condition. A sample of this size would allow us to 
detect an effect of $f=0.18$ with $95 \%$ power. In total, 404 MTurk participants completed our study in exchange for $\$ 1$. Based on preregistered criteria, we excluded four participants who did not identify as White (non-Hispanic), six participants who incorrectly answered the attention check regarding the content of the materials, and 12 participants who indicated that they did not read the materials in full. The resulting final sample included 382 participants $\left(M_{\text {Age }}=40.6, S D=\right.$ $12.5 ; 55 \%$ women). Most (57.3\%) self-identified as politically liberal.

Procedure. This study utilized a 4-cell (greater URM benefit, equal benefit, greater nonURM benefit, and control) between-subjects design. After providing consent, participants read one of four university press releases. Participants then answered how they thought the initiative would affect White applicants' likelihood of admission to the school, followed by various measures of ideological beliefs. Participants then provided demographic information and were debriefed.

Materials. Each press release described a new "Diversity Leaders Program" aimed at increasing the number of underrepresented minorities (URMs) at the institution. The press releases were substantially shorter than in Study 1 and made obvious the number of applicants of each racial group admitted as a function of the policy and the overall increase in class size. Whereas we presented four separate initiatives in Study 1, participants in the current study were shown only the policy that affected admissions rates. In the control condition, the critical section stated:

Starting this year, Haas will begin implementing its new Diversity Leaders program in our full-time MBA (FTMBA) program. Under this program, we will change the admissions criteria to place greater consideration on applicants' commitment to diversity, equity, and inclusion in their personal extracurricular, and professional lives. By giving 
greater attention to applicants' passion for creating diverse organizations, we hope to attract a larger number of URMs to our applicant pool. We estimate enrolling 50 additional FTMBA students as our Diversity Leaders each year.

Across all conditions, the policy was described as increasing the overall class size, thereby mathematically increasing the chances that students of any racial background would be accepted.

In the three new conditions, we additionally specified in two separate places how nonURM and URM students would be impacted by the policy. First, this information was provided in writing. In the greater non-URM benefit condition, participants read that the school "estimates enrolling 50 additional FTMBA students—roughly 15 more URM and 35 more non-URM students—as Diversity Leaders each year.” In the greater URM benefit condition, the school expected 35 more URM and 15 more non-URM students. In the equal benefit condition, the school expected 25 more URM and 25 more non-URM students. Second, participants were shown a figure (see Figure 1) giving the exact class size breakdowns for the year before the policy (2019-20) and after (2020-21). 

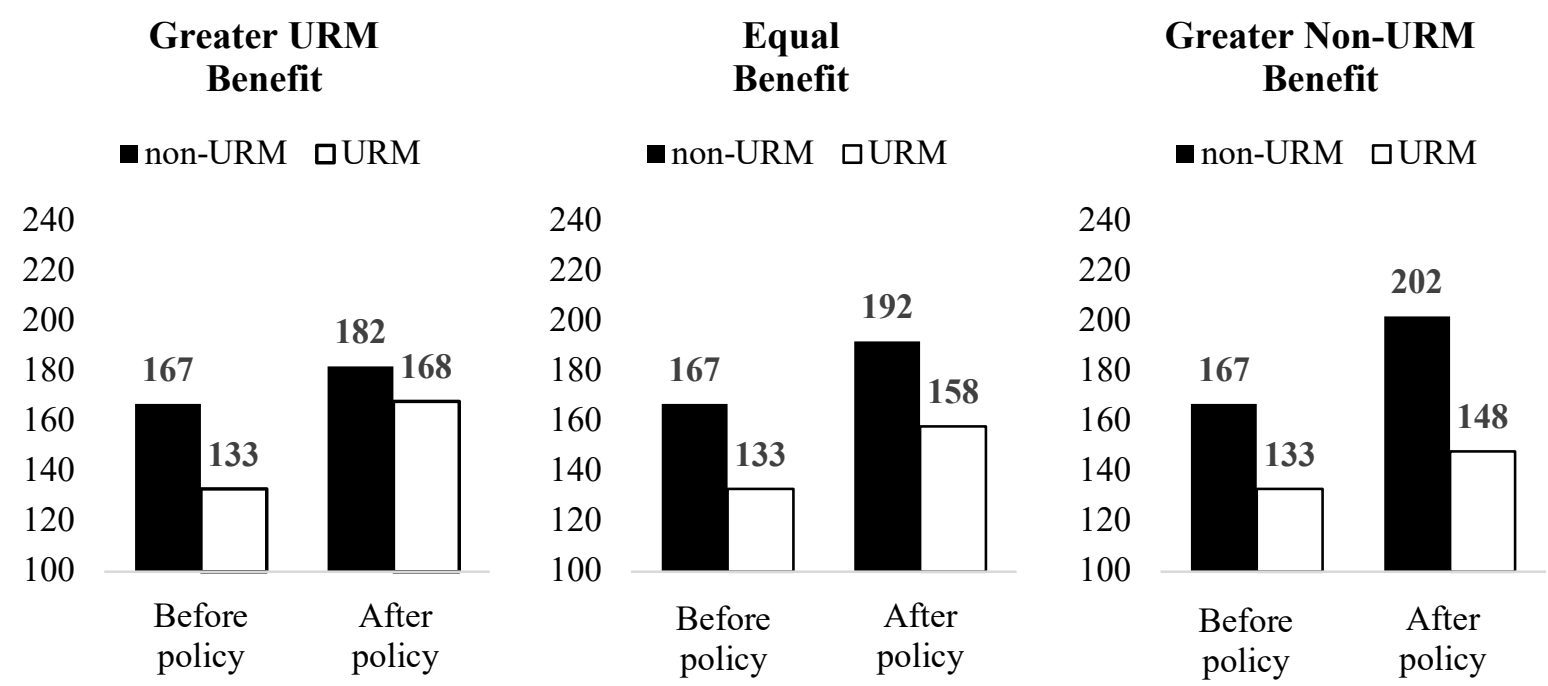

Figure 1. Projected changes to student enrollment. Examples of graphics included in Study 2 press release.

\section{Measures.}

Perceived ingroup outcome. We again asked participants: "How would the proposed initiatives affect White applicants' chances of getting accepted into Haas?' Scale recoded to -3 (greatly harm), 0 (no effect), and +3 (greatly improve).

Ideological beliefs. We collected the following measures from Study 1: anti-diversity policy beliefs $(\alpha=.90)$, political orientation $(\alpha=.94)$, SDO $(\alpha=.88)$, MRS $(\alpha=.92)$, global zero-sum beliefs $(\alpha=.87)$, symbolic threat $(\alpha=.86)$, and prototypicality threat $(\alpha=.58)$. All ideological measures were presented in a random order.

\section{Results}

Table 3 displays means and standard deviations for variables, and correlations between perceived ingroup outcome and all ideological variables. 
Table 3. Means, SD, and Correlations from Study 2 Variables

\begin{tabular}{lccc}
\hline \multicolumn{1}{c}{ Variable } & $\boldsymbol{M}$ & $\boldsymbol{S D}$ & $\begin{array}{c}\text { Perceived } \\
\text { ingroup outcome }\end{array}$ \\
\hline 1. Political orientation (overall) & 2.31 & 0.87 & $-.38^{* *}$ \\
2. Political orientation (social) & 2.17 & 0.92 & $-.37^{* *}$ \\
3. Political orientation (economic) & 2.43 & 0.91 & $-.35^{* *}$ \\
4. Social dominance orientation & 2.34 & 1.42 & $-.38^{* *}$ \\
5. Modern racism & 2.62 & 1.47 & $-.42^{* *}$ \\
6. Global zero-sum beliefs & 3.03 & 1.45 & $-.43^{* *}$ \\
7. Anti-diversity policy beliefs & 3.32 & 1.79 & $-.62^{* *}$ \\
8. Symbolic threat & 2.67 & 1.64 & $-.36^{* *}$ \\
9. Prototypicality threat & 2.74 & 1.45 & $-.37^{* *}$ \\
\hline
\end{tabular}

Note. $N=382 . * p<.05, * * p<.01 * * * p<.001$ (two-tailed).

An ANOVA revealed a weak significant effect of policy condition on perceived ingroup outcome, $F(3,378)=2.94, p=.03, \eta_{\mathrm{p}}^{2}=.02$. Post hoc comparisons using Bonferroni correction indicated that participants perceived the greater URM benefit policy as more harmful to White applicants compared to the greater non-URM benefit condition, $t(184)=2.70, p=.007,95 \% \mathrm{CI}$ $[0.13,0.86]$. All other differences between conditions were non-significant (Bonferroni-corrected ps $<.33)$.

Despite the interaction, the ANOVA revealed that participants misperceived all policies as harmful to White applicants' likelihood of acceptance, regardless of whether the policy had unspecified relative benefits (i.e., control condition; $M=-0.79, S E=0.12,95 \%$ CI [-1.03, $0.55])$, provided greater relative benefit to non-URM applicants $(M=-0.46, S E=0.13,95 \% \mathrm{CI}$ $[-0.71,-0.22])$, provided equal benefit to URM and non-URM applicants $(M=-0.62, S E=0.13$, $95 \%$ CI $[-0.86,-0.37])$, or provided greater relative benefit to URM applicants $(M=-0.96, S E=$ $0.13,95 \%$ CI [-1.20, -0.71]). See Figure 2. 


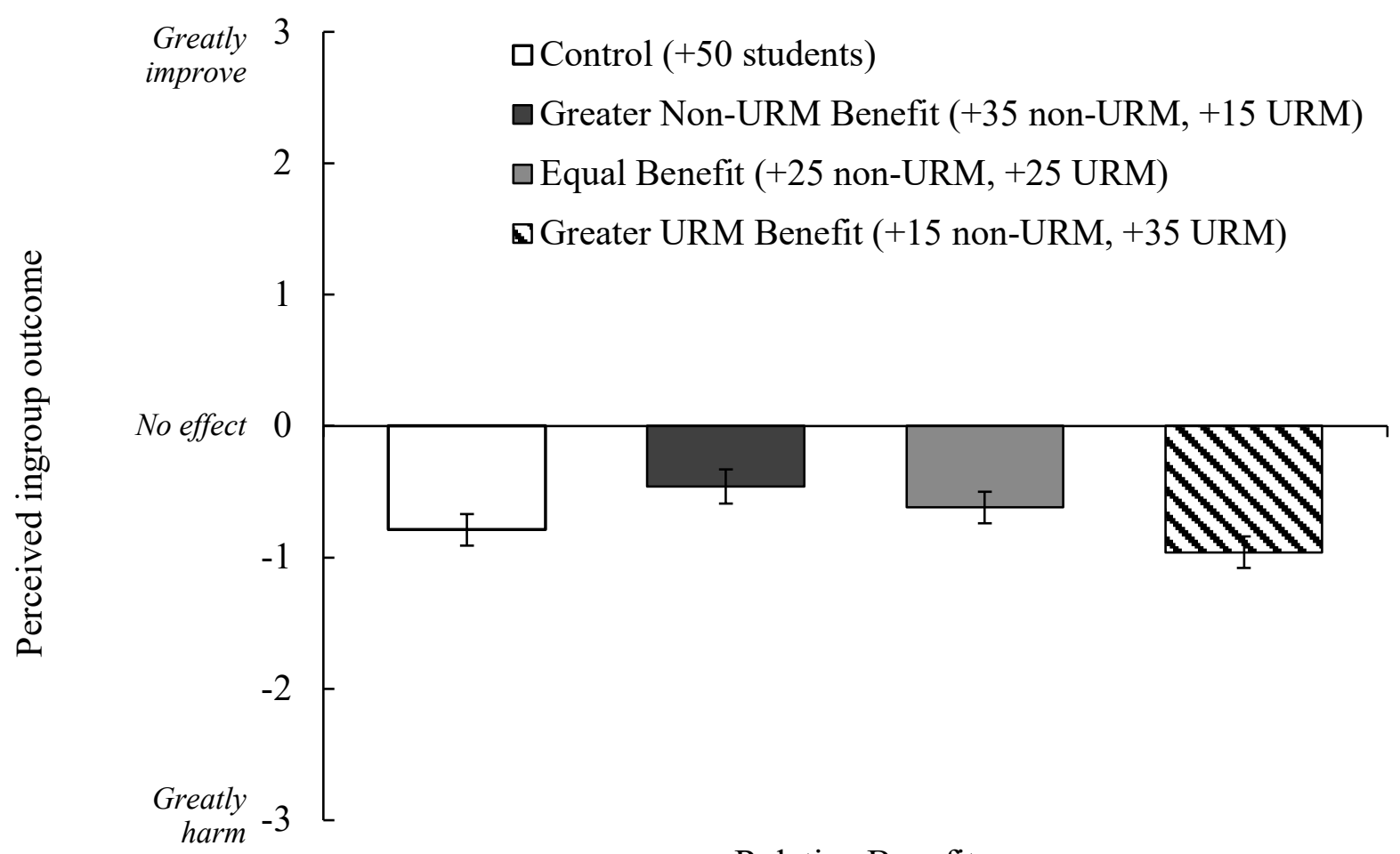

Relative Benefit

Figure 2. Study 2 participants' rating of how the proposed initiative would affect White applicants' chances of getting accepted to the school. Error bars represent $\pm S E M$.

We first accounted for participant ideologies by entering scale-centered perceived ingroup outcome as the dependent variable, condition effects as fixed factors, and mean-centered ideological belief measures as covariates into an ANCOVA. Controlling for ideological beliefs, we again found a significant effect of policy condition, $F(3,369)=3.13, p=.03, \eta_{\mathrm{p}}{ }^{2}=.03$. Participants again misperceived all four policies as harming White applicants' likelihood of acceptance: policy not specifying relative group benefit $(M=-0.75, S E=0.10,95 \%$ CI [-0.94, 0.57], greater non-URM benefit $(M=-0.46, S E=0.10,95 \%$ CI $[-0.65,-0.27]$, equal benefit $[M=$ $-0.74, S E=.10,95 \%$ CI $[-0.93,-0.55]$, and greater URM benefit $(M=-0.87, S E=0.10,95 \%$ CI $[-1.07,-0.68]$. 
We next examined whether ideological beliefs interacted with policy condition by conducting a series of linear regressions. ${ }^{9}$ We found no significant two-way interactions between condition and any ideological belief measure $(.93>p \mathrm{~s}>.56) .{ }^{10}$

\section{Discussion}

White participants misperceived non-zero-sum diversity policies as harmful to the ingroup's likelihood of being accepted even when these policies clearly and explicitly benefited them. Additionally, we found that White individuals perceived these diversity policies as harmful even when the absolute benefit to each group was the same (i.e., equal benefit condition) and when the policy actually worsened representational inequality (i.e., greater non-URM benefit condition). These results are consistent with research showing that diversity initiatives generally evoke negative reactions among majority group members (e.g., Dover et al., 2016; Lowery et al., 2012; Plaut et al., 2011; Shteynberg et al., 2011). Building on that work, participants misperceived each diversity policy as harmful to their racial group even after controlling for myriad ideological beliefs. The effects of condition also were not moderated by ideology. Thus, White participants appear to generally perceive a policy as less beneficial to the ingroup merely due to it having the stated goal of increasing diversity. We directly test this possibility in Study 3.

\section{Study 3}

Study 3 tested the extent to which majority members' misperceptions are driven by the relative benefit a policy provides to the ingroup versus driven by the rationale behind the policy. First, we manipulated whether the non-zero-sum policy provided greater benefit to URM

\footnotetext{
${ }^{9}$ The moderation analyses reported in Studies 2-4 were not preregistered but were included at the request of reviewers.

${ }^{10}$ See SOM Tables S6-7 for full reporting of condition x ideology interactions, estimated marginal means, and 95\% CIs for $\pm 1 \mathrm{SD}$ on each ideological belief measure for each condition.
} 
students or to non-URM students. Second, we manipulated whether the policy was framed as intending to increase diversity or not. We predicted either main effects of both relative benefit and framing, or an interaction between the two.

We also examined whether ideological beliefs causally influenced the observed effects. Past research has shown that manipulating perceptions of intergroup dynamics can shift participants' ideology (Danbold \& Huo, 2015; Guimond et al., 2003; Levin, 1996). For example, White participants primed with multiculturalism or increasing diversity report higher SDO (Morrison et al., 2010) and greater political conservatism (Craig \& Richeson, 2014). We therefore tested whether the effects of relative benefit and framing on perceived ingroup outcome would be explained by corresponding increases in oppositional ideology.

\section{Method}

We preregistered sample and analysis plan on OSF (https://osf.io/e2mx6).

Participants. We recruited a sample size of 400 White (non-Hispanic) U.S. citizens, with 100 participants per condition. A sample of this size allowed us to detect an interaction effect size of $f=0.25$ with at least $95 \%$ power. In total, 408 MTurk participants completed the study in exchange for $\$ 1$. Based on preregistered criteria, we excluded seven participants who did not identify as White (non-Hispanic), 14 participants who incorrectly answered the first attention check regarding the content of the materials, and ten participants who indicated that they did not read the materials in full. The resulting final sample included 377 participants $\left(M_{\text {Age }}=40.7, S D=\right.$ $13.1 ; 57.6 \%$ women). Most (54.9\%) self-identified as politically liberal.

Procedure and Materials. We manipulated relative benefit and policy framing in a $2 \times 2$ between-subjects design. Once again, participants read a university press release describing a proposed policy. Participants were randomly assigned to read either about a "Diversity Leaders 
Program" diversity frame condition or a "Promising Leaders Program" in the leadership frame condition. The diversity frame condition stated that the initiative would "place greater consideration on applicants' commitment to diversity, equity, and inclusion in their application," and focus "greater attention to applicants' passion for creating diverse organizations." In contrast, the leadership frame condition stated that the initiative would "place greater consideration on applicants' commitment to bold leadership in their application," and focus “greater attention to applicants' passion for leading teams and organizations." As in previous studies, the policy was framed as applicable to people of all backgrounds.

Participants were also randomly assigned to see that the policy provided greater benefit to either URM or non-URM students. In the greater URM benefit condition, participants read that the university "estimates enrolling 50 additional students-roughly 35 more URM students and 15 more non-URM students — as Diversity Leaders [Promising Leaders] each year." In the greater non-URM benefit condition, 15 more URM and 35 more non-URM students were expected. As in Study 2, we presented bar charts that reflected the proposed changes to the class size. ${ }^{11}$ Participants answered how they thought the initiative would affect White applicants' likelihood of admission to the school, followed by ideological measures. Participants then answered demographic questions and were debriefed.

\section{Measures}

\footnotetext{
${ }^{11}$ As in Study 1, we informed the assertion that participants misperceived the policy by determining how participants felt the greater URM benefit/leadership framing would affect the number of White applicants to the school. Pilot study participants $(N=53)$ viewed the stimuli and answered the following question (Kraus et al., 2017): "For every 100 White applicants that applied to Haas before this initiative, how many White applicants do you think will apply to Haas after this initiative goes into effect. (100 would mean the number of White applicants will not change.)" Participants reported that the onset of the policy would have no effect on the number of White people who would apply to the school, $M=102.94, S D=43.97, t(52)=0.49, p=.63,95 \%$ CI $[90.82,115.06]$, again indicating that the increased class size described in the stimuli should indeed be perceived as increasing applicants' chances of admission.
} 
Perceived ingroup outcome. We again asked participants: "How would the proposed initiatives affect White applicants' chances of getting accepted into Haas?" Scale recoded to -3 (greatly harm), 0 (no effect), and +3 (greatly improve).

Ideological beliefs. We collected the following measures from Studies 1 and 2: antidiversity policy beliefs ( $\alpha=.88)$, political orientation $(\alpha=.93), \operatorname{SDO}(\alpha=.87), \operatorname{MRS}(\alpha=.90)$, global zero-sum beliefs $(\alpha=.85)$, and symbolic threat $(\alpha=.81)$. We also collected two new ideological measures:

System justifying beliefs. Eight items assessed perceptions of U.S. social system legitimacy (Kay \& Jost, 2003; $\alpha=.87$ ): "In general, you find society to be fair," "In general, the American political system operates as it should," "American society needs to be radically restructured" (reverse-scored), "The United States is the best country in the world to live in," "Most policies serve the greater good," "Everyone has a fair shot at wealth and happiness," "Our society is getting worse every year" (reverse-scored), "Society is set up so that people usually get what they deserve"; 1 (strongly disagree) to 7 (strongly agree).

Procedural fairness. Three items assessed perceptions of the proposed initiative's fairness $(\alpha=.93)$ : "All applicants will be evaluated fairly," "Evaluation of applicants will be unbiased," "Applications will be evaluated consistently across all applicants"; 1 (strongly disagree) to 7 (strongly agree).

All ideological measures were presented in a random order.

\section{Results}

Table 4 displays means and standard deviations for variables, and correlations between perceived ingroup outcome and all ideological variables. 
Table 4.

Means, SD, and Correlations from Study 3 Variables

\begin{tabular}{lccccc}
\hline \multicolumn{1}{c}{ Variable } & $\boldsymbol{M}$ & $\boldsymbol{S D}$ & $\begin{array}{c}\text { Relative } \\
\text { Benefit }^{\mathbf{a}}\end{array}$ & $\begin{array}{c}\text { Policy } \\
\text { Framing }^{\mathbf{b}}\end{array}$ & $\begin{array}{c}\text { Perceived } \\
\text { ingroup } \\
\text { outcome }\end{array}$ \\
\hline 1. Political orientation (overall) & 2.37 & 0.83 & .05 & -.03 & $-.14^{* *}$ \\
2. Political orientation (social) & 2.25 & 0.88 & .06 & -.03 & $-.17^{* *}$ \\
3. Political orientation (economic) & 2.48 & 0.85 & .08 & -.005 & $-.16^{* *}$ \\
4. Social dominance orientation & 2.36 & 1.31 & -.001 & $-.15^{* *}$ & $-.21^{* * *}$ \\
5. Modern racism & 2.62 & 1.26 & -.001 & $-.12^{*}$ & $-.27^{* * *}$ \\
6. Symbolic threat & 2.68 & 1.44 & -.01 & -.04 & $-.25^{* * *}$ \\
7. Global zero-sum beliefs & 3.12 & 1.30 & .09 & .04 & $-.29^{* * *}$ \\
8. System justifying beliefs & 3.71 & 1.21 & -.02 & -.005 & -.009 \\
9. Anti-diversity policy beliefs & 3.45 & 1.69 & -.06 & $-.13^{*}$ & $-.41^{* * *}$ \\
10. Procedural fairness & 4.13 & 1.58 & -.10 & .02 & $.43^{* * *}$ \\
\hline
\end{tabular}

Note. $N=377 . * p<.05, * * p<.01, * * * p<.001$ (two-tailed).

${ }^{a}$ Relative Benefit is dummy coded as $0=$ greater non-URM benefit, $1=$ greater URM benefit

${ }^{\mathrm{b}}$ Policy Framing is dummy coded as $0=$ Leadership framing, $1=$ Diversity framing

As predicted, a 2 (Relative Benefit: greater URM benefit vs. greater non-URM benefit) $\mathrm{x}$ 2 (Policy Framing: Diversity vs. Leadership) between-subjects ANOVA revealed main effects of both relative benefit, $F(1,372)=6.54, p=.01, \eta_{\mathrm{p}}{ }^{2}=.02$, and policy framing, $F(1,372)=4.16, p$ $=.04, \eta_{\mathrm{p}}{ }^{2}=.01$, on perceived ingroup outcome, and a significant interaction of relative benefit and policy framing, $F(1,372)=7.73, p=.006, \eta_{\mathrm{p}}{ }^{2}=.02 .{ }^{12}$

The effect of relative benefit was significant when the policy used a leadership framing, $F(1,372)=14.30, p<.001$, but not when it used a diversity framing, $F(1,372)=0.03, p=.86$. Additionally, the effect of policy framing was significant when the policy provided greater nonURM benefit, $F(1,372)=11.86, p<.001$, but not when it provided greater URM benefit, $F(1$, $372)=0.27, p=.60$. Specifically, participants perceived a diversity framed policy as harmful to White applicants' likelihood of acceptance regardless of whether the policy provided greater URM benefit $(M=-0.50, S E=.12,95 \%$ CI $[-0.74,-0.27])$ or greater non-URM benefit $(M=$ -

\footnotetext{
${ }^{12}$ A post hoc power analysis using this effect size $(f=.14)$ revealed that we obtained $62.9 \%$ power. Code for all power analyses are available on OSF.
} 
$0.53, S E=.12,95 \%$ CI $[-0.76,-0.29])$. Participants also perceived a leadership policy that provided greater benefit to URM students as harmful to the ingroup $(M=-0.59, S E=.12,95 \%$ CI $[-0.83,-0.35])$. Only when the policy both was framed as being unrelated to diversity and bestowed greater benefit to the ingroup did participants perceive the policy as unharmful $(M=$ $0.05, S E=.12,95 \%$ CI $[-0.18,0.28])$. See Figure 3 .

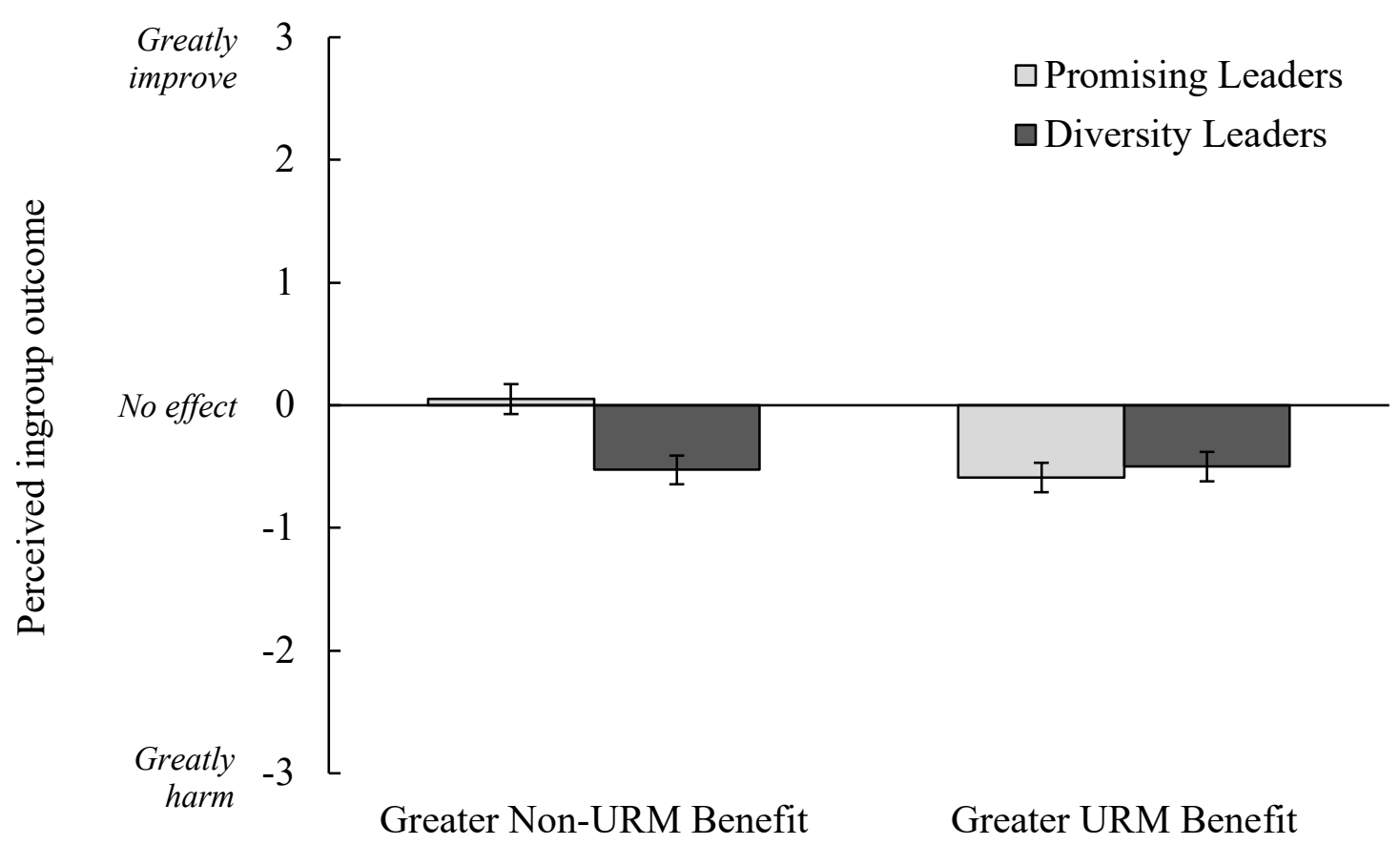

Figure 3. Study 3 participants' ratings of how the proposed initiative would affect White applicants' chances of getting accepted to the school. Error bars represent $\pm S E M$.

We first accounted for participant ideologies by entering perceived ingroup outcome as the dependent variable, condition effects (including their interaction) as fixed factors, and meancentered ideological belief measures as covariates into an ANCOVA. Controlling for ideological beliefs, we found a significant effect of relative benefit, $F(1,194)=7.03, p=.009, \eta_{\mathrm{p}}{ }^{2}=.04$, a nonsignificant main effect of policy framing, $F(1,194)=2.63, p=.11, \eta_{\mathrm{p}}{ }^{2}=.01$, and a weakly 
significant interaction of the two, $F(1,194)=3.95, p=.05, \eta_{\mathrm{p}}{ }^{2}=.02$. Once again, participants perceived a diversity framed policy as harmful to White applicants' likelihood of being accepted regardless of whether the policy provided greater benefit to URMs $(M=-0.58, S E=0.13,95 \%$ CI $[-0.83,-0.32])$ or non-URMs $(M=-0.48, S E=0.14,95 \%$ CI $[-0.76,-0.20])$. Once again, participants perceived a leadership policy as harmful to White applicants' acceptance rates when the policy provided greater benefit to URMs $(M=-0.63, S E=0.14,95 \%$ CI $[-0.90,-0.36])$, but not when it provided greater benefit to non-URMs $(M=0.02, S E=0.14,95 \%$ CI $[-0.26,0.29])$.

We next examined whether ideological beliefs moderated the effects of relative benefit and framing conditions by conducting a series of linear regressions. The three-way interactions between ideology and experimental conditions were nonsignificant for all variables (.94 $\geq p s \geq$ $.07),{ }^{13}$ except for a weakly significant interaction for anti-diversity policy beliefs, $B=0.30, S E=$ $0.14, t(284)=2.14, p=.03,95 \%$ CI $[0.02,0.58]$. For participants high in anti-diversity policy beliefs (+1 SD), we found a significant two-way interaction between relative benefit and policy framing, $B=1.36, S E=0.34, t(284)=3.97, p<.001,95 \% \mathrm{CI}[0.68,2.03]$. The effect of relative benefit was significant in the leadership framing condition, such that greater URM benefit was perceived as less beneficial than greater non-URM benefit, $B=-1.24, S E=0.22, t=-5.58, p<$ $.001,95 \%$ CI $[-1.68,-0.80]$. However, the effect of relative benefit was not significant in the diversity framing condition, $B=0.11, S E=0.26, t=0.44, p=.66,95 \%$ CI $[-0.40,0.62]$. For participants low in anti-diversity beliefs (-1 SD) the interaction between relative benefit and policy framing was not significant, $B=0.33, S E=0.34, t(284)=0.97, p=.33,95 \%$ CI $[-0.34$, 0.99].

\footnotetext{
${ }^{13}$ See SOM Tables S9-10 for full reporting of condition x ideology interactions, estimated marginal means, and 95\% CIs for \pm 1 SD on each ideological belief for each condition.
} 
Finally, we directly tested whether participants' self-reported ideological beliefs explained the interactive effect of relative policy benefit and policy framing conditions on perceived ingroup outcomes. ${ }^{14}$ In a 10,000 bootstrapped moderated mediation model (PROCESS, Model 8; Hayes, 2012) we tested policy framing as the predictor, relative benefit as the moderator, and all ideological measures as simultaneous mediators. The conditional interactive effect of policy framing and relative benefit on perceived ingroup outcome remained weakly significant, $B=0.55, S E=0.27, t=1.99, p=.048,95 \%$ CI $[0.004,1.09]$. This interaction was not significant for any of the various potential ideological mediators $(.88>p \mathrm{~s}>.17$; though the effect on procedural fairness was marginal, $B=0.84, S E=0.44, t=1.90, p=.06,95 \%$ CI [$0.03,1.71]$ ), indicating a lack of significant indirect effect (see SOM Table S11 for full statistics). As expected, even accounting for all potential ideological mediators, the conditional direct effect of policy framing remained significant when the policy provided greater benefit to non-URMs, $B=0.49, S E=0.20, t=2.51, p=.01,95 \%$ CI $[-0.88,-0.11]$, such that diversity framing was perceived as less beneficial to the ingroup than leadership framing. In contrast, when the policy provided greater benefit to URMs, there was no difference in how beneficial participants perceived either framing was to the ingroup, $B=0.052, S E=0.19, t=0.27, p=.79$, $95 \%$ CI $[-0.32,0.43]$.

\section{Discussion}

White participants perceived non-zero-sum policies as harming White applicants' likelihood of being accepted not only when the policy was framed around diversity but also when the policy benefited their ingroup relatively less than it did minority groups. As a result, a

\footnotetext{
${ }^{14}$ The moderated mediation analysis was not preregistered but was included at the request of a reader.
} 
policy that increased minority representation was perceived as harmful even if the policy benefited White people and was not motivated by pro-diversity rationales.

The results of this study largely support our hypothesis that these effects are not due to diversity-related ideologies. As in Studies 1 and 2, the main findings hold true even when controlling for myriad ideological measures. Shifts in ideology also did not significantly mediate the effects of policy framing and relative benefit on participants' perceptions. Finally, ideologies mostly did not moderate the observed effects. Only the anti-diversity policy belief scale interacted with policy framing and relative benefit. Specifically, participants who were more generally opposed to diversity policies, but not those who generally supported them, significantly demonstrated the reported effects. The observed pattern of results was therefore largely independent from the effects of ideology, if not completely.

\section{Study 4}

In Studies 1-3, the policy benefit that White students received relative to racial minorities was confounded with the absolute size of the benefit they receive. This issue is particularly clear in Study 3 when the initiative is framed as a leadership policy: White participants who learned that a leadership policy would add more slots for the ingroup than for racial minorities (i.e., +35 to non-URMs versus +15 to URMs) were also led to expect more slots for the ingroup overall compared to the condition where racial minorities received greater benefit (i.e., only +15 to non$U R M s$ versus +35 to URMs). It is therefore arguable that the decrease in additional spots for non-URM students from 35 to 15 drove the observed effect. In contrast, we hypothesize that majority group members misperceive the effect non-zero-sum policies have on their ingroup because they focus on how the ingroup is disadvantaged relative to the outgroup, regardless of how much better off a policy makes their group in an absolute sense. We therefore manipulated 
both the policy's relative and absolute benefits in Study 4. We predicted that White participants would have more negative perceptions of policies providing relatively greater benefit to URMs but would not have more negative perceptions of policies providing less absolute benefit. To better test this hypothesis, we removed all diversity framing from the policy description and exclusively used the leadership framing from Study 3.

We also used the current design to conduct a final stringent test of ideological beliefs as possible mediators or moderators in the observed effects thus far. We therefore doubled our sample size to better detect small effects. We hypothesize that White participants' misperceptions are not merely driven by adversarial ideology toward diversity policies but by viewing such policies through the lens of majority group membership.

Finally, we addressed the possibility that the effects observed in Studies 1-3 might be driven by stereotypes about the particular university mentioned in the stimuli. We therefore changed the university to a school that was seen as equal status by participants but is historically more conservative and less polarizing of an institution.

\section{Method}

We preregistered sample and analysis plan on OSF (https://osf.io/6c45r).

Participants. We planned to collect 800 White (non-Hispanic) U.S. citizens, targeting 200 participants per condition. This sample size would be large enough to detect the relative benefit effect size in Study $3(f=.13)$ with $96 \%$ power. In total, 808 people participated in our experiment in exchange for $\$ 1$. Based on preregistered exclusion criteria, we excluded 15 participants who did not identify as White (non-Hispanic), 20 participants who incorrectly answered the first attention check regarding the content of the materials, and nine participants who indicated that did not read the materials in full. The resulting final sample included 764 
participants $\left(M_{\text {Age }}=40.3, S D=12.8 ; 54.7 \%\right.$ women $)$. Most $(59.7 \%)$ self-identified as politically liberal.

Procedure and materials. The study design was the same as Study 3, but with the following changes: First, the school mentioned in the press release was changed to Georgetown University. In a separate pretest sample $(N=186)$, we asked participants to rank six universities. ${ }^{15}$ We computed an average rank for each school and compared them to UC Berkeley. A paired-samples $t$-test revealed that UC Berkeley $(M=3.19, S D=1.34)$ and Georgetown University $(M=3.53, S D=1.92)$ were ranked similarly, $t(185)=1.76, p=.08$.

Second, the policy in all conditions was written using the "Promising Leaders" framing from Study 3. Thus, the only indication that the policy would have divergent effects on students of each racial group was found in the estimated number of admits from each group.

Finally, we manipulated the policy's absolute benefit and relative benefit in a new $2 \times 2$ between-subjects design. To manipulate absolute benefit, we randomly assigned participants to see that the class size would increase by 50 students (high absolute benefit condition), as in Studies 2 and 3, or by 10 students (low absolute benefit condition). To manipulate relative benefit, we randomly assigned participants to see that a greater proportion of the additional slots were expected to go either to URMs (greater URM benefit condition) or to non-URMs (greater non-URM benefit condition). Specifically, participants read one of the following racial breakdowns for the additional slots: 40 URM [non-URM] vs 10 non-URM [URM]; 8 URM [non-URM] vs. 2 non-URM [URM] students. As in Studies 2 and 3, this information was both

\footnotetext{
15 The six universities were: Duke, UCLA, Emory, UC Berkeley, Georgetown University, Carnegie Mellon University. The universities are ordered by rank on U.S. News \& World Report 2020 Best National University Rankings list. In the pretest, participants ranked each university in order of preference: "Please rank the following schools by dragging them into the order that you would attend, with 1 being your most preferred option and 6 being your least preferred option."
} 
written and represented graphically. Notably, White applicants always received more slots in the high absolute benefit condition than in the low absolute condition. Therefore, White applicants' likelihood of acceptance were always mathematically greater in the high absolute benefit condition compared to the low absolute benefit condition, regardless the relative benefit to each racial group.

Measures. We collected the following measures from previous studies: political orientation (overall, economic, and social; $\alpha=.94)$, $\operatorname{SDO}(\alpha=.84)$, MRS $(\alpha=.89)$, global zerosum beliefs ( $\alpha=.85)$, group status threat (single-item), symbolic threat $(\alpha=.82)$, prototypicality threat $(\alpha=.34)$, and procedural fairness $(\alpha=.95)$. We also included measures of diversity policy attitudes and group esteem that have been as mediators in prior research on diversity policy perceptions:

Anti-diversity policy beliefs. Four items assessed participants' diversity policy support (Unzueta \& Binning, 2012; $\alpha=.91$ ): "The school should implement policies that promote diversity" (reverse-scored), "This school needs to make an effort to improve its level of diversity" (reverse-scored), "Improving diversity should not be a concern at this school", and "Improving diversity should not be a priority at this school".

Ingroup esteem. Four items assessed participants' esteem for their racial ingroup (Lowery et al., 2012; $\alpha=.86)$ : "I often regret that I belong to my racial/ethnic group" (reverse-scored), “In general, I’m glad to be a member of my racial/ethnic group, “Overall, I often feel that my racial/ethnic group is not worthwhile" (reverse-scored), "I feel good about the race/ethnicity I belong to"; 1 (strongly disagree) and 7 (strongly agree).

\section{Results}


Table 5 displays means and standard deviations for variables, and correlations between perceived ingroup outcome and all ideological variables.

Table 5.

Means, SD, and Correlations from Study 4 Variables

\begin{tabular}{lccccc}
\hline \multicolumn{1}{c}{ Variable } & $\boldsymbol{M}$ & $\boldsymbol{S D}$ & $\begin{array}{c}\text { Relative } \\
\text { Benefit }^{\mathbf{a}}\end{array}$ & $\begin{array}{c}\text { Absolute } \\
\text { Benefit }^{\mathbf{b}}\end{array}$ & $\begin{array}{c}\text { Perceived ingroup } \\
\text { outcome }^{\text {Butcon }}\end{array}$ \\
\hline 1. Political orientation (overall) & 2.30 & 0.86 & -.03 & .02 & $.20^{* * *}$ \\
2. Political orientation (social) & 2.16 & 0.91 & .01 & -.02 & $-.13^{* *}$ \\
3. Political orientation (economic) & 2.42 & 0.90 & .04 & -.013 & $-.13^{* *}$ \\
4. Social dominance orientation & 2.21 & 1.23 & -.001 & .012 & $-.11^{* *}$ \\
5. Modern racism & 2.54 & 1.27 & .05 & -.04 & $-.13^{* * *}$ \\
6. Symbolic threat & 2.40 & 1.41 & -.004 & .004 & $-.11^{* *}$ \\
7. Prototypicality threat & 2.49 & 1.18 & -.002 & .02 & $-.15^{* * *}$ \\
8. Group status threat & 3.71 & 1.65 & -.008 & -.01 & $-.12^{* *}$ \\
9. Global zero-sum beliefs & 2.89 & 1.29 & .02 & .03 & -.07 \\
10. Ingroup esteem & 5.48 & 1.22 & .02 & -.01 & $-.10^{* *}$ \\
11. Anti-diversity policy beliefs & 2.91 & 1.39 & .01 & .03 & $-.10^{* *}$ \\
12. Procedural fairness & 4.61 & 1.59 & -.06 & .03 & $.31^{* * *}$ \\
\hline
\end{tabular}

Note. $N=764 .{ }^{*} p<.05, * * p<.01, * * * p<.001$ (two-tailed).

a Relative Benefit was coded as $0=$ greater URM benefit, $1=$ greater Non-URM Benefit

${ }^{\mathrm{b}}$ Absolute Benefit was coded as $0=$ Low Absolute Benefit, $1=$ High Absolute Benefit

As predicted, a 2 (Relative Benefit: greater URM benefit vs. greater non-URM benefit) $\mathrm{x}$ 2 (Absolute Benefit: high vs. low) between-subjects ANOVA revealed a significant main effect of relative benefit, $F(1,759)=74.88, p<.001, \eta^{2}=.09$. As predicted, neither the main effect of absolute benefit, $F(1,759)=2.20, p=.14, \eta^{2}=.003$, nor the interaction between relative benefit and absolute benefit were significant, $F(1,759)=0.18, p=.67, \eta^{2}<.001$. 
Specifically, participants misperceived greater URM benefit policies as harmful to White applicants' likelihood of acceptance regardless of whether the policy provided low absolute impact $(M=-0.22, S E=0.09,95 \%$ CI $[-0.39,0.05])$ or high absolute impact $(M=-0.13, S E=$ $0.09,95 \%$ CI $[-0.30,0.04])$. However, participants accurately perceived greater non-URM benefit policies as improving White applicants' likelihood of acceptance regardless of whether the policy provided low $(M=0.51, S E=0.09,95 \%$ CI $[0.33,0.68])$ or high absolute impact $(M=$ $0.68, S E=0.09,95 \%$ CI $[0.50,0.85])$. See Figure 4 .

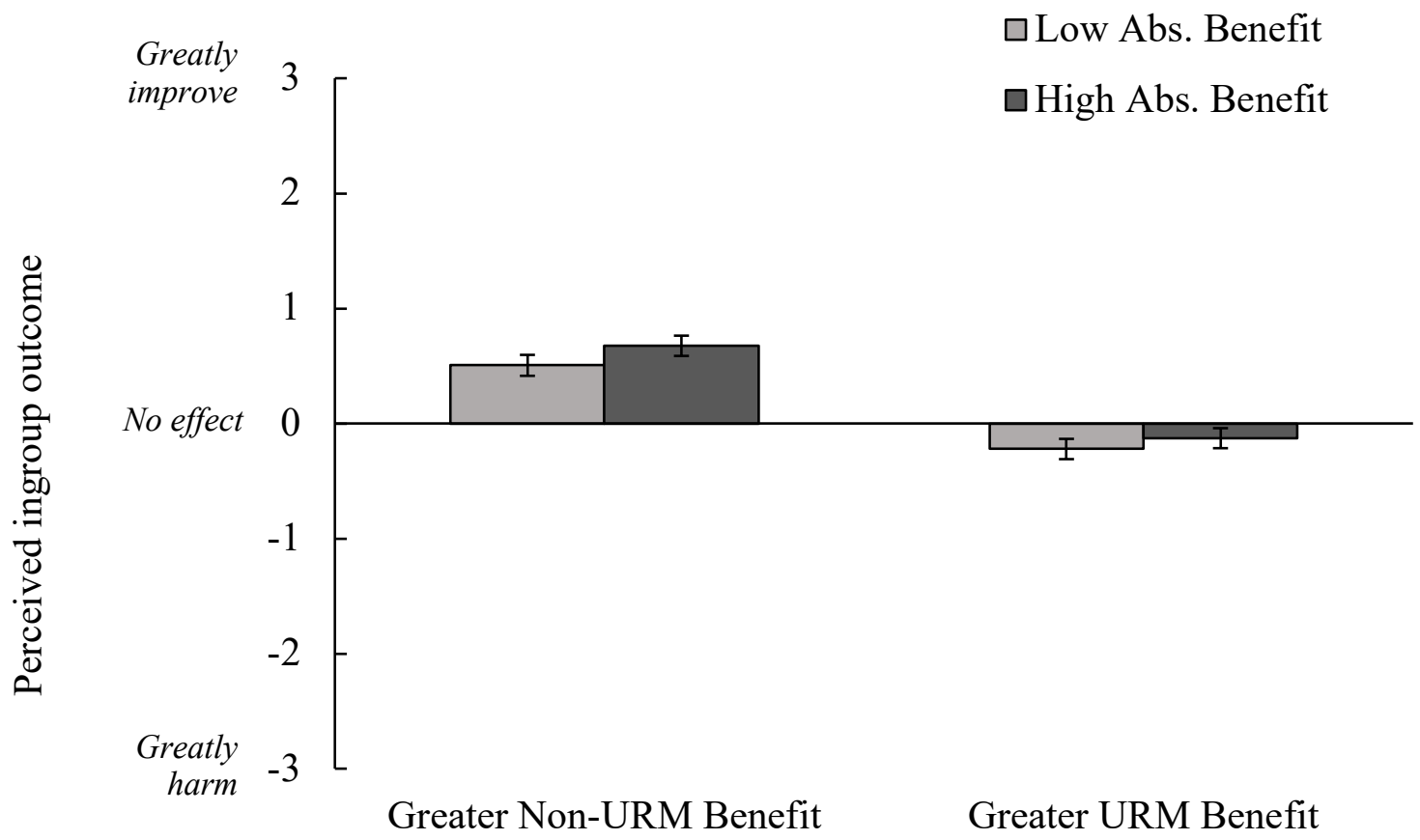

Figure 4. Study 4 participants' ratings of how the proposed initiative would affect White applicants' chances of getting accepted to the school. Error bars represent $\pm S E M$.

As in previous studies, we first accounted for participant ideologies by entering perceived ingroup outcome as the dependent variable, condition effects (including their interaction) as fixed factors, and mean-centered ideological belief measures as covariates into an ANCOVA. Controlling for ideological beliefs, we found the same overall pattern of effects: a significant 
effect of relative benefit, $F(1,747)=75.23, p<.001, \eta_{\mathrm{p}}{ }^{2}=.09$, a nonsignificant main effect of absolute benefit, $F(1,747)=1.89, p=.17, \eta_{\mathrm{p}}{ }^{2}=.003$, and a non-significant interaction of the two, $F(1,747)=0.18, p=.67, \eta_{\mathrm{p}}{ }^{2}<.001$. Once again, participants perceived policies that provided greater benefit to URMs as unbeneficial to White applicants' likelihood of being accepted regardless of whether the policy provided low $(M=-0.20, S E=0.08,95 \%$ CI $[-0.36,-$ $0.03])$ or high absolute benefit $(M=-0.12, S E=0.08,95 \% \mathrm{CI}[-0.28,0.05])$. Once again, participants perceived policies that provided greater non-URM benefit as beneficial to White applicants' acceptance rates regardless of whether the policy provided low $(M=0.50, S E=0.09$, $95 \% \mathrm{CI}[0.33,0.66])$ or high absolute benefit to applicants $(M=0.65, S E=0.08,95 \% \mathrm{CI}[0.48$, $0.81])$.

We next examined whether ideological beliefs interacted with relative benefit condition by conducting a series of linear regressions. The two-way interactions between ideology and relative benefit were nonsignificant for all variables $(0.94 \geq p s \geq 0.22)$, except for procedural fairness, $B=0.22, S E=0.08, t(755)=2.79, p=.01,95 \%$ CI $[0.06,0.37]$. Participants who viewed the policy as less procedurally fair (-1 SD) perceived the policy as more harmful to White applicants' likelihood of acceptance when it provided greater URM benefit compared to when it provided greater non-URM benefit, $B=-1.05, S E=0.12, t(755)=-8.78, p<.001,95 \%$ CI $[-1.28,-0.81]$. The same effect was apparent for participants who viewed the policy as more procedurally fair (+1 SD), although to a lesser extent: The policy was perceived as less beneficial when it provided greater URM benefit compared to when the policy provided greater non-URM benefit, $B=-0.40, S E=0.12, t(755)=-3.35, p=.001,95 \%$ CI $[-0.63,-0.16]$. 
Finally, we explored whether ideological beliefs mediated the relationship between relative policy benefit on perceived ingroup outcomes. In a 10,000 bootstrapped mediation model (PROCESS, Model 4; Hayes, 2012), we entered all ideological measures as simultaneous mediators. ${ }^{16}$ Ideological beliefs did not significantly mediate the relationship between relative benefit and perceived ingroup outcome as indicated by confidence intervals that overlap with zero (Table 6). ${ }^{17}$ As expected, the conditional direct effect of relative benefit on perceived ingroup outcome remained significant, $B=0.72, S E=0.08, t=-8.65, p<.001,95 \%$ CI $[0.56$, $0.89]$.

Table 6. Mediation Analysis of Ideological Belief Measures, Study 4

\begin{tabular}{lcccc}
\hline \multicolumn{1}{c}{ Mediator } & $\boldsymbol{B}$ & $\boldsymbol{S E}$ & LCI & UCI \\
\hline 1. Anti-diversity policy beliefs & -0.008 & 0.012 & -0.035 & 0.013 \\
2. Political orientation & -0.002 & 0.006 & -0.016 & 0.01 \\
3. Social dominance orientation & 0.003 & 0.008 & -0.012 & 0.022 \\
4. Modern racism & -0.001 & 0.008 & -0.019 & 0.016 \\
5. Zero-sum beliefs & -0.0001 & 0.008 & -0.018 & 0.017 \\
6. Ingroup esteem & 0.002 & 0.011 & -0.020 & 0.025 \\
7. Group status threat & -0.001 & 0.005 & -0.012 & 0.007 \\
8. Symbolic threat & 0.001 & 0.007 & -0.012 & 0.018 \\
9. Prototypicality threat & 0.0002 & 0.005 & -0.012 & 0.011 \\
10. Procedural fairness & -0.040 & 0.025 & -0.092 & 0.008 \\
\hline
\end{tabular}

Note. All mediators entered simultaneously into a 10,000 bootstrapped model using Model 4 of Hayes' PROCESS in SPSS. Relative Benefit ( $0=$ greater URM benefit, $1=$ greater non-URM benefit) was entered as the predictor and perceived ingroup outcome was entered as the outcome variable in this model. $\mathrm{LCI}=95 \%$ lower confidence interval, $\mathrm{UCI}=95 \%$ upper confidence interval.

\footnotetext{
${ }^{16}$ As PROCESS allows for a maximum of 10 mediators to be entered simultaneously, we entered a composite political orientation measure that was the average of social, economic, and overall orientation $(\alpha=.94)$.

${ }^{17}$ See SOM Tables S13-14 for full reporting of interactions, estimated marginal means, and 95\% CIs for \pm 1 SD on each ideological belief measure for each condition.
} 


\section{Discussion}

We found that White participants misperceived non-zero-sum leadership policies as harmful to their ingroup's likelihood of being accepted solely as a function of whether their ingroup received relatively less benefit from the policy than the outgroup. The absolute number of White students benefiting from the policy did not matter: White participants perceived policies which provided non-URM students 10 additional slots (but URM students would receive 40) as harmful and policies which provided non-URM students only 8 additional slots (versus 2 to URMs) as beneficial. In effect, participants reported more positive perceptions of a policy that exacerbated representational inequality than of a policy that both reduced inequality and made their racial ingroup even better off.

With increased power through a doubled sample size, we once again found scant evidence that this effect was driven by ideology. The effect again persisted when controlling for ideology and was not mediated by ideological variables. Ideologies again mostly did not moderate the observed effects. Furthermore, and contrary to Study 3, anti-diversity beliefs were no longer a significant moderator. Instead, only procedural fairness beliefs interacted with relative benefit. Yet even this result provided little support for the idea that the observed effect requires ideological opposition. That is, White participants who most strongly believed in the procedural fairness of the policy still perceived policies providing greater relative benefit to URM students as less beneficial to their ingroup, regardless of the absolute benefit conferred to their group.

\section{Study 5}

Without consistent evidence in support of an ideological explanation for the observed effect, we tested whether misperceptions of ingroup outcome depend on majority group 
membership. In our previous studies, we focused solely on participants from the numerical majority, whether in U.S. society generally or in a particular university context. Due to the general pervasiveness of zero-sum thinking (Johnson et al., 2020; Meegan, 2010; Thompson \& Hastie, 1990), it is plausible that minority group members also misperceive policies increasing minority representation as being unbeneficial to the majority group. However, prior work suggests that majority group members are more inclined than minority group members to exhibit zero-sum thinking in intergroup contexts (e.g., Esses et al., 2001; Norton \& Sommers, 2011; Wilkins et al., 2015). This tendency has been attributed to advantaged group members' motivation to maintain their position in the social hierarchy (Kteily \& Richeson, 2016). In line with this thinking, we predicted that White participants, compared to Black participants, would perceive non-zero-sum policies as less beneficial to majority member (i.e., White) applicants. Additionally, we tested whether White and Black participants would have divergent perceptions of White applicants' outcomes as a function of whether a policy provided greater benefit to URMs or greater benefit to non-URMs.

\section{Method}

We preregistered sample and analysis plan on OSF (https://osf.io/p4cse).

Participants. We planned to collect 400 U.S. citizens, targeting 200 White Americans and 200 Black Americans. This sample would be large enough to detect an effect size of $f=.25$ for an ANOVA main effect of participant race with at least $95 \%$ power. In total, 412 people participated in this study in exchange for $\$ 1$. Based on preregistered criteria, we excluded six participants who identified as neither White (non-Hispanic) nor Black/African-American, 27 participants who incorrectly answered the first attention check regarding the content of the materials, and 17 participants who indicated they did not read the materials in full. The resulting 
final sample included 362 participants. Black $\left(n=176 ; M_{\text {Age }}=37.5, S D=12.9,64.8 \%\right.$ women $)$ and White participants ( $n=186 ; M_{\text {Age }}=36.4, S D=11.5,54.3 \%$ women $)$ mostly self-identified as politically liberal $\left(73.3 \%_{\text {Black }} ; 64.5 \%\right.$ White $)$.

Procedure and materials. As in Studies 3 and 4, participants read a press release describing a new "Promising Leaders Program". Participants were randomly shown a policy that either provided greater benefit to URM or to non-URM students using the same manipulations as in Study 3. Ideological beliefs were not measured in the current study, but survey materials were otherwise identical to Study 3.

\section{Measures}

Perceived majority group outcomes. Each participant indicated, "How would the proposed initiatives affect White applicants' chances of getting accepted into Haas?" Scale recoded to -3 (greatly harm), 0 (no effect), and +3 (greatly improve).

\section{Results}

As predicted, a 2 (Relative Benefit: greater URM benefit vs greater non-URM benefit) x 2 (Participant Race: Black vs. White) between-subjects ANOVA revealed main effects of both relative benefit, $F(1,355)=6.44, p=.01, \eta_{\mathrm{p}}{ }^{2}=.018$, and participant race, $F(1,355)=10.38, p=$ $.001, \eta_{\mathrm{p}}{ }^{2}=.03$, on perceived ingroup outcome. A weakly significant interaction of relative benefit and participant also emerged, $F(1,355)=4.08, p=.04, \eta_{\mathrm{p}}^{2}=.01$.

The effect of relative benefit was significant for White participants, $F(1,355)=14.05, p$ $<.001$, but not for Black participants, $F(1,355)=0.71, p=.40$. Additionally, the effect of participant race was significant only when the policy provided greater URM benefit, $F(1,355)=$ $10.69, p=.001$, and not when the policy provided greater non-URM benefit, $F(1,355)=0.13, p$ $=.72$. Specifically, White participants misperceived the greater URM benefit policy as 
unbeneficial to White applicants' likelihood of acceptance $(M=-0.14, S E=0.12,95 \%$ CI $[-0.38$, 0.10]). However, White participants correctly perceived the greater non-URM benefit policy as improving White applicants' likelihood of acceptance $(M=0.53, S E=0.13,95 \%$ CI $[0.27$, 0.79]). In contrast, Black participants accurately perceived the policies as improving White applicants' likelihood of acceptance regardless of whether the policies provided greater nonURM benefit $(M=0.60, S E=0.13,95 \%$ CI $[0.34,0.85])$ or greater URM benefit $(M=0.44, S E$ $=0.13,95 \%$ CI $[0.19,0.70])$. See Figure 5 .

\section{Discussion}

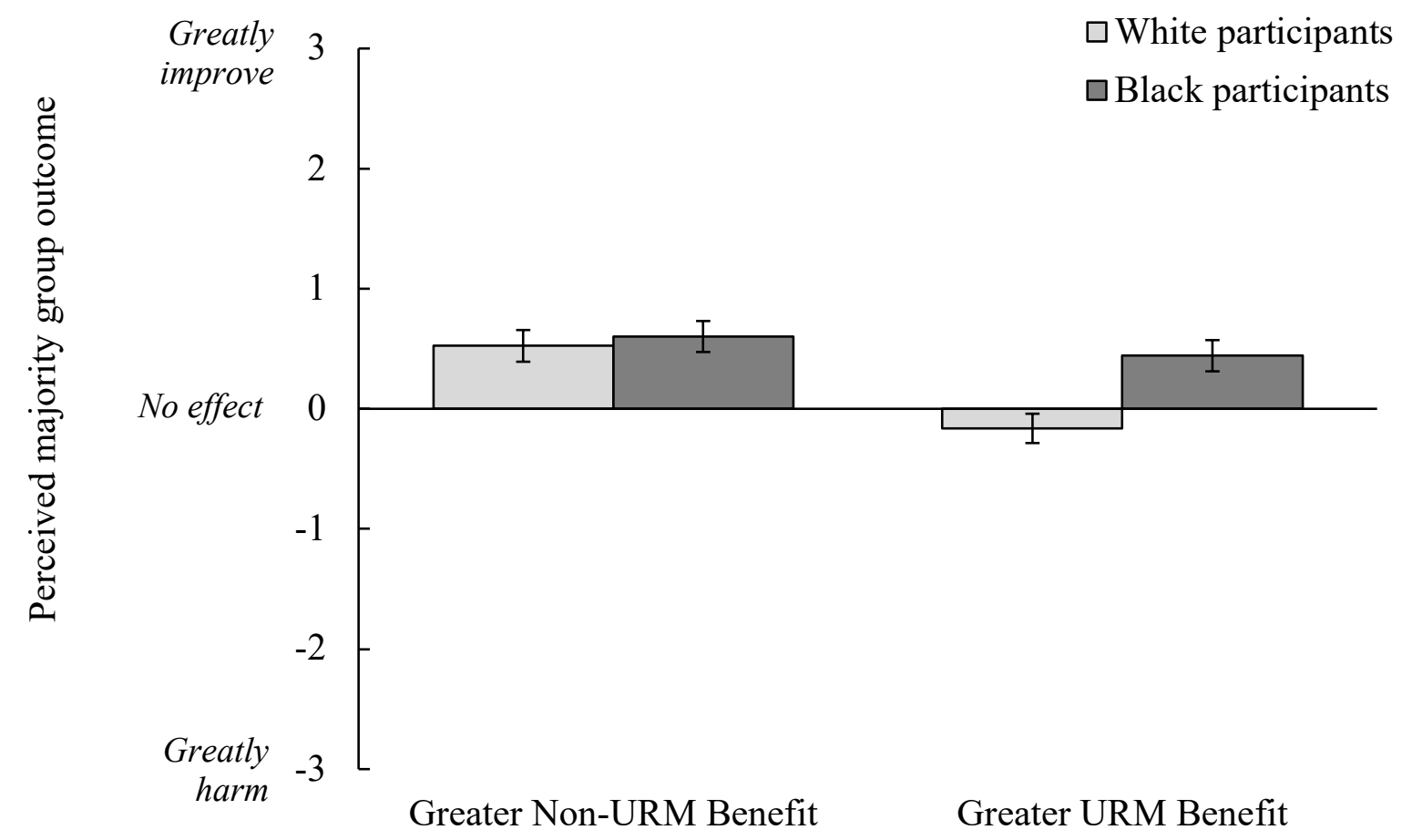

Figure 5. Study 5 participants' ratings of how the proposed initiative would affect White applicants' chances of getting accepted to the school. Error bars represent $\pm S E M$.

White participants again misperceived non-zero-sum policies as unbeneficial to White applicants' likelihood of acceptance when the policy benefited minorities relatively more than the ingroup. In contrast, Black (i.e., minority) participants accurately perceived that non-zerosum policies benefited White applicants regardless of which group received the larger share of 
the pie. We next tested whether White individuals who are represented as members of the minority group perceive these policies in a similar manner as Black participants in the current study.

\section{Study 6}

We manipulated whether White participants read a policy press release from a majority White institution or from a majority Black — and therefore minority White-institution. We predicted that White participants would misperceive the effect of a non-zero-sum policy on majority applicants only when White people were in the numerical majority but not when they were in the minority.

\section{Method}

We preregistered sample and analysis plan on OSF (https://osf.io/3a4rj)

Participants. We planned to collect 200 White (non-Hispanic) U.S. citizens, targeting 100 participants per condition. This sample size would detect the effect size in Study $5(d=.27)$ with $48 \%$ power. In total, 205 MTurk participants completed this study in exchange for $\$ 1$. Based on preregistered criteria, we excluded four participants who did not identify as White (non-Hispanic), six participants who incorrectly answered the first attention check regarding the content of the materials, and three participants who indicated that did not read the materials in full. The resulting final sample included 192 participants $\left(M_{A g e}=38.1, S D=13.3 ; 57.3 \%\right.$ women). Most (60\%) self-identified as politically liberal.

Procedure and materials. In a 2-cell (White majority vs. White minority) betweensubjects design, participants read about the "Promising Leaders" program from previous studies but proposed either at Haas School of Business (White majority) or at Howard University's School of Business (White minority). In the White minority condition, the press release 
mentioned that Howard University is a top member of the consortium of historically Black colleges and universities. Participants in both conditions were told that the minority group would receive greater benefit from the policy. In the White majority condition, participants read that Haas "estimates enrolling 50 additional students-roughly 35 more URM students and 15 more non-URM students — as Promising Leaders each year.” In the White minority condition, participants read that Howard University's School of Business “estimates enrolling 50 additional students_-roughly 35 more White (non-Hispanic) students and 15 more Black/Latinx studentsas Promising Leaders each year." As in previous studies, we presented bar charts that reflected the proposed changes to the class size. Aside from the majority and minority group labels mentioned above, these bar charts were identical. At the end of the study, we collected participants' demographics and debriefed them.

Perceived group outcomes. Participants were asked how the policy would affect majority group members in the following manner: "How would the proposed initiatives affect White [Black] applicants' chances of getting accepted into Haas?" Scale recoded to -3 (greatly harm) to 0 (no effect) to +3 (greatly improve).

Materials otherwise matched those from Study 5.

\section{Results}

We conducted an independent samples $t$-test with White students' numerical representation as the independent variable and perceived majority group outcome as the dependent measure. As predicted, White participants perceived the policy as providing less benefit to majority applicants' likelihood of acceptance when in the numerical majority $(M=$ $0.07, S D=1.25)$ than when in the minority $(M=1.06, S D=1.36), t(190)=-5.26, p<.001,95 \%$ CI [-1.36, -0.62] (Figure 6). 
One-sample $t$-tests revealed that, when in the majority group, White participants misperceived that the policy would not benefit majority applicants' likelihood of acceptance, $t(97)=0.56, p=.57,95 \%$ CI $[-0.18,0.32]$. In contrast, when in the minority, White participants accurately perceived that the policy would improve majority applicants' likelihood of acceptance, $t(93)=7.59, p<.001,95 \%$ CI $[0.79,1.34]$.

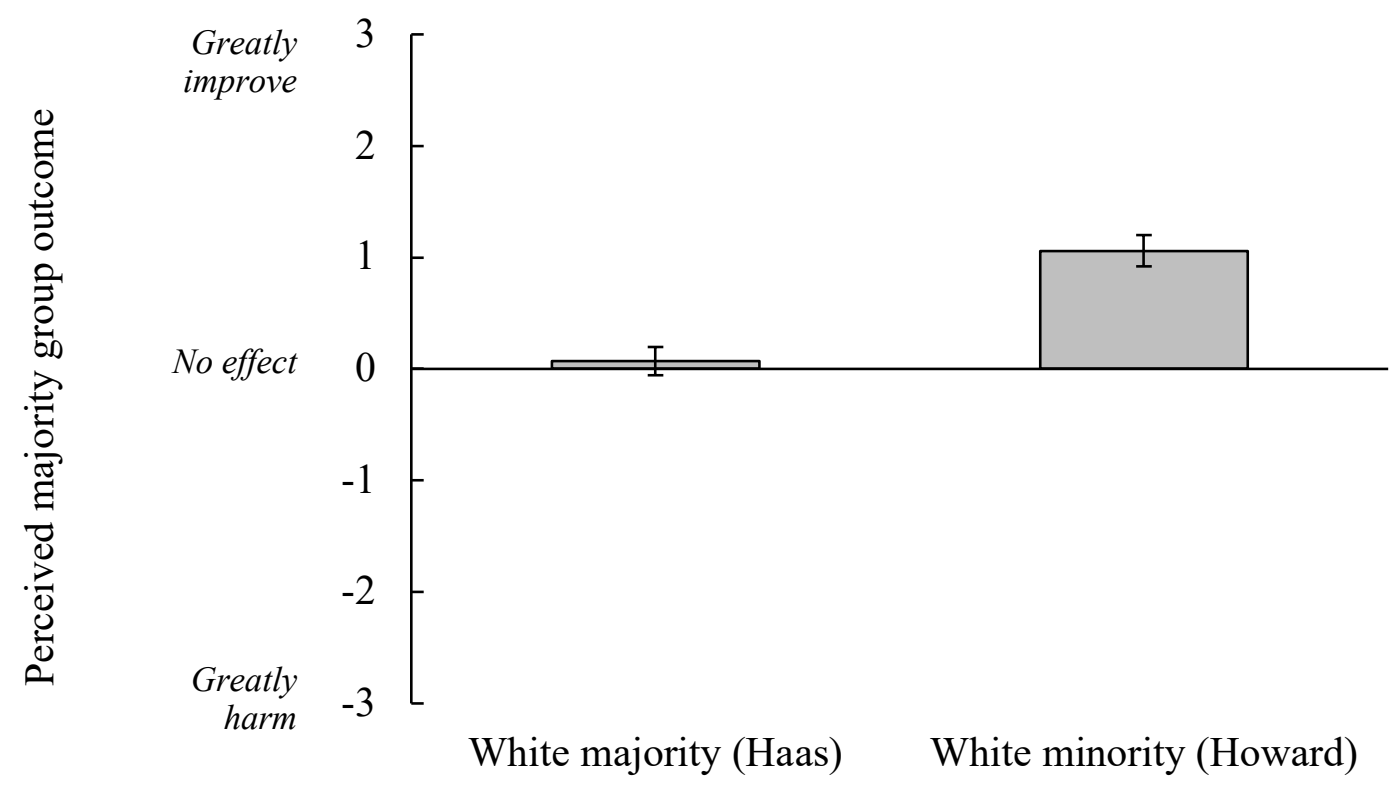

Figure 6. Study 6 participants' ratings of how the proposed initiative would affect the majority groups' chances of getting accepted to the school. Error bars represent $\pm S E M$.

\section{Discussion}

We found direct evidence that a majority group lens causes misperceptions of policies that increase minority representation. Once again, White participants in the numerical majority misperceived a policy as unbeneficial to majority group applicants' likelihood of acceptance. However, when White people were in the numerical minority, they accurately perceived the same policy as benefiting the majority group, exactly as Black participants did in Study 5 (see Figure 5).

\section{General Discussion}


The answer to why diversity policies are widely supported yet infrequently effective has remained elusive for some time. Although a wealth of past research reveals how an individual's stated ideological beliefs predict perceptions of diversity policies, increases in national support for diversity policies have not translated into implementation. Across six studies speaking to this problem, we show that majority group members generally misperceived how diversity policies would affect their ingroup. Specifically, we found that White and Asian Americans misperceived any university initiative labeled a "diversity" policy as unbeneficial—and at times harmful—to their ingroup's likelihood of being accepted to the school. This was true despite the policy increasing admission rates for White and Asian applicants. Troublingly, majority group members perceived ostensible "diversity" policies as harmful to their ingroup even when the policies actually maintained or worsened representational disparities between the majority and minority group. When instead framed as "leadership" policies, majority group members still misperceived them as unbeneficial to their group if the minority group received greater benefit relative to the majority group. This finding held true regardless of the absolute number of majority members who would actually benefit from the policy, suggesting that a focus on relative outcomes alone explained majority members' misperceptions. Only when a policy gave majority group members a larger "slice of the pie" and was not explicitly framed around diversity did majority members correctly perceive it as beneficial to their group. Unfortunately, such policies only increased representational inequality.

Self-reported ideological beliefs around diversity, by and large, did not explain the effect that a policy's diversity framing and relative group benefits had on majority members' perceptions. We found consistent evidence that majority group members misperceived policy effects when controlling for numerous self-reported ideological beliefs (i.e., general opposition 
to diversity policies, political orientation, explicit prejudice, social dominance orientation, system justification, procedural fairness perceptions, group threats, etc.; Studies 1-4). We furthermore found no evidence that the myriad ideologies statistically mediated our effects (Studies $3 \& 4$ ). And we found only meager and inconsistent evidence that ideologies moderated these effects. Egalitarian and inegalitarian participants alike perceived "diversity" policies that exacerbated representational inequality as more beneficial than policies that both reduced inequality and made their ingroup even better off (Study 4).

Instead, we primarily found evidence that the observed effects were driven by viewing diversity policies through a majority group lens. In contrast to White and Asian Americans (i.e., members of the majority in the university context we studied), Black Americans correctly identified the university initiatives as benefiting majority group members regardless of who received greater benefit (Study 5). This pattern was not due to Black Americans' unique abilities of perception: When White participants were assigned to identify with the minority group by evaluating a policy at a historically Black university, they also correctly perceived that the initiative benefited the majority group (Study 6).

\section{Majority Group Membership and Diversity Ideology}

The present research extends our understanding of how group membership shapes perception (e.g., Dovidio \& Gaertner, 2010; Hastorf \& Cantril, 1954; Phillips et al., 2006). These findings complement existing work illustrating how group membership produces divergent perceptions of how diversity should be pursued (Unzueta \& Binning, 2012), what the goal of diversity initiatives should be (Leslie, 2019), or even what constitutes diversity and fair policy outcomes (Bauman et al., 2014; Danbold \& Unzueta, 2020). In line with other past work, we find that judgments about redistributive policies are determined by the social position of one's 
ingroup, independent of concerns for the well-being of the outgroup (e.g., Lowery et al., 2006).

Ours builds on these studies to show that majority group members generally form unduly negative impressions of diversity initiatives, even when such initiatives are painstakingly crafted to simultaneously benefit the majority group.

These results comport with the theory that being a member of the majority group increases the impetus to preserve one's advantages (Kteily \& Richeson, 2016). Mere identification with an advantaged group increases one's favoring of consistently superior outcomes for that group (Tajfel \& Turner, 1979). Simultaneously, higher standing within the social hierarchy increases one's motivation to maintain the existing social order (Richeson \& Sommers, 2016; Unzueta \& Lowery, 2008). Majority group membership also predicts perceptions of inequality in ways that may make support for equalizing policies less likely. For example, White Americans are motivated to overestimate the extent to which society has achieved racial and economic equality (Kraus et al., 2017; 2019; Onyeador et al., 2020). These misperceptions of inequality in turn predict decreased support for redistributive policies (Jackson \& Payne, 2020). It therefore may be that members of overrepresented groups (i.e., White and Asian) are more likely than members of underrepresented groups (i.e., Black and Latinx) to underestimate extant disparities in educational opportunities, to perceive policies that would rectify these disparities as undercutting existing advantages, and to be more likely to subsequently oppose them.

The generalizability of the present effects is an unanswered question of both theoretical and practical importance. Our theorization would predict that the observed tendency broadly applies to groups advantaged with status and power in contexts where policies aim to challenge the status quo. Other researchers have argued as much, for example highlighting that zero-sum 
thinking pervades gender dynamics in similar ways to racial dynamics (Kehn \& Ruthig, 2013; Wilkins et al., 2015). That said, the present paper cannot definitively rule out that the effects are dependent on the specific history of race-focused diversity policies, Western settings, or Whiteness within American institutions (Rabelo et al., 2020; Ray, 2019). For example, the prominent ongoing public debate over the legality of affirmative action in the United States could have shaped our White American participants' response to the policies they evaluated. Our results appear not to be fully dependent on such sociocultural factors, however, given that White individuals accurately perceived diversity policies as beneficial to the majority group when White people were represented as part of the minority (Study 6). Nonetheless, it will be valuable for future research to identify the extent to which these misjudgments apply across various cultures, institutional contexts, and group identities. Future research might also employ minimal groups paradigms in which group membership and status are experimentally manipulated in order to more definitively identify the extent to which they drive these effects.

Our findings align with recent evidence that the effects of majority group membership on social perceptions can occur orthogonally to the influence of one's stated ideological leanings (Ballinger \& Crocker, 2020, cf. Plaut et al., 2011; Wetherell et al., 2013). For example, Dover and colleagues (2016) showed that majority group members are threatened by diversity policies irrespective of their self-reported prejudice, group status threat, social dominance, racial/ethnic identification, or political orientation. This is not to say that ideological beliefs do not matter. A robust prior literature shows that ideologies shape perceptions of diversity initiatives and, more generally, social inequality (e.g., Davidai \& Ongis, 2020; Federico \& Sidanius, 2002; Kteily et al., 2017; Lowery et al., 2012; Phillips \& Lowery, 2020; Plaut et al., 2011; Walker et al., 2007). Likewise, our participants' stated ideologies often strongly correlated with their perceptions of 
how diversity policies would affect their ingroup. For example, participants higher in social dominance, anti-Black attitudes, anti-diversity attitudes, and political conservatism perceived diversity policies as less beneficial than participants lower on these measures. Yet our data frequently revealed that people who expressed pro-egalitarian beliefs_-politically liberal, low on social dominance orientation, or pro-Black, for instance-still perceived diversity policies as overall unbeneficial or harmful to their group, just like those with anti-egalitarian beliefs (see SOM). It remains an open question, of course, whether an unmeasured ideology causally explains our effect. Furthermore, we measured all ideological variables via self-report, making them susceptible to self-presentational concerns. Such concerns may have led participants to downplay their inegalitarianism (e.g., Crandall et al., 2002; Dovidio \& Gaertner, 2000), reducing construct validity and hindering our ability to test how ideologies related to our results. Nonetheless, after utilizing a wide variety of measures that are highly predictive of diversity policy perceptions, we find that egalitarian attitudes do not simply undo the effect of majority group membership.

We also note that we found some, although limited, evidence that diversity policy perceptions may sometimes depend on majority members' ideologies. We found that the more participants believed that diversity initiatives are generally helpful (Study 3) or the specific policy was procedurally fair (Study 4), the less likely they were to show the observed effects. This evidence is reminiscent of past findings that majority group members often believe that diversity policies do more harm than good (Dover et al., 2016; Jones et al., 2019; Nishii et al., 2018) and are inherently unfair (Gu et al., 2014; Hideg \& Ferris, 2017; Leslie, 2019). However, we must note that we were unable to replicate either moderation effect in our paper. Furthermore, neither greater pro-diversity policy beliefs nor greater procedural fairness beliefs 
predicted perceiving policies that increase diversity as more beneficial than those that did not increase diversity. For example, participants who believed procedural fairness was high still perceived policies with greater URM benefit as less beneficial to their group than policies with greater non-URM benefit, regardless of whether the absolute size of the benefit was larger or not. Support for ideological explanations to our results must therefore be considered underwhelming. But future work is needed to systematically examine how and when group membership and ideology together produce impactful interactive effects (e.g., Hudson et al., 2019; Ponce de Leon et al., 2020).

Considering our results and the existing literature together, we argue it is a mistake to principally focus on ideological opposition to diversity (e.g., political conservatism, SDO, explicit prejudice, system justifying beliefs) in order to explain why diversity is stymied. Attributing the failures of diversity and inclusion efforts to ideologically opposed individuals implies that ideologically supportive individuals are not responsible when progress flags (Daumeyer et al., 2019). Our results fit within a growing body of work showing that people with self-avowed egalitarian beliefs also engage in inegalitarian tendencies (e.g., Dover et al., 2016; Dupree \& Fiske, 2019; Jacoby-Senghor et al., 2021; Rosenblum et al., 2021). Outside of psychology, philosophers and economists have remarked that even "good" White people play a role in preserving inequality (Sullivan, 2014) and that those who are best off often "hoard" the opportunities that others lack (Reeves, 2017). From historical civil rights leaders (King, 1963, pp. 9-10) to present-day law and sociology scholars (e.g., Alexander, 2020; Morris, 2020), there is an enduring dialogue about the failure of White allies to do more than espouse egalitarian ideals and directly redress the inequalities that minority groups face. We hope researchers are encouraged to explore the possibility that people who hold seemingly egalitarian ideological 
beliefs can nonetheless perpetuate systems of inequality, wherein diversity remains an unremitting challenge.

\section{Implementation of Effective Diversity Policies}

Ideally, non-zero-sum policies would circumvent the belief that diversity comes at a cost to the majority group by providing mutual benefit to majority and minority groups.

Unfortunately, this was not the case: The actual benefit enjoyed by the majority group was irrelevant to majority members' perceptions of the policy's effect on their group. Instead, majority members predominantly focused on how a policy impacted their ingroup relative torather than irrespective of - the outgroup. As a result, participants often saw themselves as worse off when they in fact were the opposite.

Our evidence aligns with a wealth of research showing that people are predisposed to see the world in zero-sum terms (e.g., Davidai \& Ongis, 2019; Esses et al., 2001; Johnson et al., 2020; Meegan, 2010; Sirola \& Pitesa, 2017). For instance, negotiators often assume their interests are opposed, thwarting their ability to find mutually beneficial, or 'win-win', solutions (Thompson \& Hastie, 1990). People also often feel deprived if they receive less of a resource than other individuals or groups, regardless of how well off they are overall (Crosby, 1976; Halevy et al., 2010). But majority members may at times be more predisposed than minority members to perceive intergroup outcomes in zero-sum terms. For example, Norton and Sommers (2011) illustrated that, rather than viewing diminishing levels of anti-Black prejudice as a benefit to all of society, White Americans believe this trend corresponds to increasing anti-White prejudice. Our findings emphasize that majority group members' zero-sum thinking in situations that are not zero-sum may lead them to self-defeating conceptions of what constitutes a beneficial policy. 
However, it is important to note that our findings emerge from a specific policy presented in a similar context across each study. Future work should examine whether zero-sum tendencies lead individuals to undermine their own welfare across other contexts, identities, and cultures. It is also worth noting that the policies across most of our experimental conditions would result in a lower proportion of White students at the institution than are in the general population. For example, in most of the greater non-URM benefit conditions, the proportion of additional admission slots going to non-URM students (70\%) was lower than the current White population in the U.S. (76\%; U.S. Census Bureau, 2020). The resultant decrease in proportional representation for White and Asian students could be reasonably interpreted as zero-sum. That said, all the policies we utilized were expected to increase admissions rates for majority members rather than decrease admissions rates, as majority participants perceived. White participants also correctly viewed the same policy as increasing majority members' admission rates when the university was predominantly Black (Study 6). Our findings are therefore consistent with the interpretation that majority members paid less attention to whether equal representation was achieved than to whether a status quo that benefited them was preserved.

Practically, our results suggest that the architects of diversity policies must rely on more than stated support within their organizations as they attempt to institute representational changes. Although measures of support can provide useful insights about a diversity policy's appeal, these methods likely will miss the full picture. For example, even in organizations that tout diversity as a core value, majority group members can continue to see diversity policies are exclusionary (e.g., Plaut et al., 2011) or unfair (Shteynberg et al., 2014). Therefore, efforts to increase the egalitarian attitudes of members of an organization (e.g., through bias training) are likely insufficient to effectively increase the representation of minorities. To the extent that 
majority members focus on how diversity policies will affect them relative to others, instead of the absolute benefits their group will enjoy, policymakers might consider making the benefits provided to majority group members salient (Marques, 2008; Molnar et al., 2016). Future work should also explore the barriers inherent to realizing when a policy is zero-sum versus when a policy is not. In particular, practitioners would benefit from understanding whether majority members might at times prefer policies that advantage one's group at the expense of others, as opposed to policies that benefit one group without affecting another or policies that make all groups better off. In sum, researchers and practitioners alike should consider the possibility that effective policy may generally be viewed negatively by the majority.

\section{Conclusion}

Research has long demonstrated that majority members have negative reactions to policies that increase the representation of minority members, typically in contexts that are zerosum. In considering non-zero-sum diversity policies - those explicitly designed to benefit everyone-we find that members of the majority group still fail to identify the policy's intended joint benefits. This appears to be true even when ostensible diversity policies do not improve- or actually reduce - the overall representation of underrepresented groups. Researchers and practitioners alike may wish to consider whether policies intended to ameliorate representational disparities will be deemed beneficial by the majority only when these policies are designed to fail at their goal. 


\section{References}

Alexander, M. (2020, June 8). America, this is your chance. The New York Times. https://www.nytimes.com/2020/06/08/opinion/george-floyd-protests-race.html

Apfelbaum, E. P., Phillips, K. W., \& Richeson, J. A. (2014). Rethinking the baseline in diversity research: Should we be explaining the effects of homogeneity? Perspectives on Psychological Science, 9(3), 235-244. https://doi.org/10.1177/1745691614527466

Avery, D. R. (2003). Reactions to diversity in recruitment advertising--are differences black and white? Journal of Applied Psychology, 88(4), 672-679. https://doi.org/10.1037/0021$\underline{9010.88 .4 .672}$

Avery, D. R. (2011). Support for diversity in organizations: A theoretical exploration of its origins and offshoots. Organizational Psychology Review, 1(3), 239-256. https://doi.org/10.1177/2041386611402115

Balliet, D., Tybur, J. M., Wu, J., Antonellis, C., \& Van Lange, P. A. (2018). Political ideology, trust, and cooperation: In-group favoritism among Republicans and Democrats during a US national election. Journal of Conflict Resolution, 62(4), 797-818. https://doi.org/10.1177/0022002716658694

Balliet, D., Wu, J., \& De Dreu, C. K. W. (2014). Ingroup favoritism in cooperation: A metaanalysis. Psychological Bulletin, 140(6), 1556-1581. https://doi.org/10.1037/a0037737

Ballinger, T., \& Crocker, J. (2020). Understanding Whites' perceptions of multicultural policies: A (non)zero-sum framework? Journal of Personality and Social Psychology. Advance online publication. https://doi.org/10.1037/pspi0000315

Bauman, C. W., Trawalter, S., \& Unzueta, M. M. (2014). Diverse according to whom? Racial group membership and concerns about discrimination shape diversity 
judgments. Personality and Social Psychology Bulletin, 40(10), 1354-1372. https://doi.org/10.1177/0146167214543881

Bazerman, M. H. (1983). Negotiator judgment: A critical look at the rationality assumption. American Behavioral Scientist, 27(2), 211-228. https://doi.org/10.1177/000276483027002007

Bell, J. M., \& Hartmann, D. (2007). Diversity in everyday discourse: The cultural ambiguities and consequences of "happy talk". American Sociological Review, 72(6), 895-914. https://doi.org/10.1177/000312240707200603

Ben-Ner, A., McCall, B. P., Stephane, M., \& Wang, H. (2009). Identity and in-group/out-group differentiation in work and giving behaviors: Experimental evidence. Journal of Economic Behavior \& Organization, 72(1), 153-170. https://doi.org/10.1016/j.jebo.2009.05.007

Birnbaum, H. J., Stephens, N. M., Townsend, S. S., \& Hamedani, M. G. (2020). A diversity ideology intervention: Multiculturalism reduces the racial achievement gap. Social Psychological and Personality Science, Advance online publication. https://doi.org/10.1177/1948550620938227

Budiman, A. (2020, October 1). Americans are more positive about the long-term rise in U.S. racial and ethnic diversity than in 2016. Pew Research Center. https://www.pewresearch.org/fact-tank/2020/10/01/americans-are-more-positive-aboutthe-long-term-rise-in-u-s-racial-and-ethnic-diversity-than-in-2016/

Castano, E., Yzerbyt, V., Bourguignon, D., \& Seron, E. (2002). Who may enter? The impact of in-group identification on in-group/out-group categorization. Journal of Experimental Social Psychology, 38(3), 315-322. https://doi.org/10.1006/jesp.2001.1512 
Castilla, E. J., \& Benard, S. (2010). The paradox of meritocracy in organizations. Administrative Science Quarterly, 55(4), 543-676. https://doi.org/10.2189/asqu.2010.55.4.543

Chow, R. M., \& Knowles, E. D. (2015). Taking race off the table: Agenda setting and support for color-blind public policy. Personality and Social Psychology Bulletin, 42(1), 25-39. https://doi.org/10.1177/0146167215611637

Cikara, M., Bruneau, E., Van Bavel, J. J., \& Saxe, R. (2014). Their pain gives us pleasure: How intergroup dynamics shape empathic failures and counter-empathic responses. Journal of Experimental Social Psychology, 55, 110-125. https://doi.org/10.1016/j.jesp.2014.06.007

Craig, M. A., \& Richeson, J. A. (2014). On the precipice of a "majority-minority" America: Perceived status threat from the racial demographic shift affects white Americans' political ideology. Psychological Science, 25(6), 1189-1197. https://doi.org/10.1177/0956797614527113

Craig, M. A., Rucker, J. M., \& Richeson, J. A. (2018). The pitfalls and promise of increasing racial diversity: Threat, contact, and race relations in the 21 st century. Current Directions in Psychological Science, 27(3), 188-193. https://doi.org/10.1177/0963721417727860

Crandall, C. S., Eshleman, A., \& O'Brien, L. (2002). Social norms and the expression and suppression of prejudice: The struggle for internalization. Journal of Personality and Social Psychology, 82(3), 359-378. https://doi.org/10.1037/0022-3514.82.3.359

Crosby, F. (1976). A model of egoistical relative deprivation. Psychological Review, 83(2), 85113. https://doi.org/10.1037/0033-295X.83.2.85

Danbold, F., \& Huo, Y. J. (2015). No longer “All-American”? Whites' defensive reactions to their numerical decline. Social Psychological and Personality Science, 6(2), 210-218. https://doi.org/10.1177/1948550614546355 
Danbold, F., \& Unzueta, M. M. (2020). Drawing the diversity line: Numerical thresholds of diversity vary by group status. Journal of Personality and Social Psychology, 118(2), 283-306. https://doi.org/10.1037/pspi0000182

Daumeyer, N. M., Onyeador, I. N., Brown, X., \& Richeson, J. A. (2019). Consequences of attributing discrimination to implicit vs. explicit bias. Journal of Experimental Social Psychology, 84, 103812. https://doi.org/10.1016/j.jesp.2019.04.010

Davidai, S., \& Ongis, M. (2019). The politics of zero-sum thinking: The relationship between political ideology and the belief that life is a zero-sum game. Science Advances, 5(12), eaay3761. https://doi.org/10.1126/sciadv.aay3761

Dawes, C. T., Fowler, J. H., Johnson, T., McElreath, R., \& Smirnov, O. (2007). Egalitarian motives in humans. Nature, 446, 794-796. https://doi.org/10.1038/nature05651

Dezsö, C. L., \& Ross, D. G. (2012). Does female representation in top management improve firm performance? A panel data investigation. Strategic Management Journal, 33(9), 1072-1089. https://doi.org/10.1002/smj.1955

Dover, T. L., Major, B., \& Kaiser, C. R. (2016). Members of high-status groups are threatened by pro-diversity organizational messages. Journal of Experimental Social Psychology, 62, 58-67. https://doi.org/10.1016/j.jesp.2015.10.006

Dovidio, J. F., \& Gaertner, S. L. (2010). Intergroup bias. In S. T. Fiske, D. T. Gilbert, \& G. Lindzey (Eds.), Handbook of Social Psychology (5th ed., pp. 1084 -1121). Wiley.

Dupree, C. H., \& Fiske, S. T. (2019). Self-presentation in interracial settings: The competence downshift by White liberals. Journal of Personality and Social Psychology, 117(3), 579604. https://doi.org/10.1037/pspi0000166 
Eagle, N., Macy, M., \& Claxton, R. (2010). Network diversity and economic development. Science, 328(5981), 1029-1031. https://doi.org/10.1126/science.1186605

Earle, M., \& Hodson, G. (2020). Questioning white losses and anti-white discrimination in the United States. Nature Human Behaviour, 4(2), 160-168. https://doi.org/10.1038/s41562019-0777-1

Eibach, R. P., \& Keegan, T. (2006). Free at last? Social dominance, loss aversion, and white and black Americans' differing assessments of racial progress. Journal of Personality and Social Psychology, 90(3), 453-467. https://doi.org/10.1037/0022-3514.90.3.453

Esses, V. M., Dovidio, J. F., Jackson, L. M., \& Armstrong, T. L. (2001). The immigration dilemma: The role of perceived group competition, ethnic prejudice, and national identity. Journal of Social Issues, 57(3), 389-412. https://doi.org/10.1111/0022$\underline{4537.00220}$

Esses, V. M., Jackson, L. M., \& Armstrong, T. L. (1998). Intergroup competition and attitudes toward immigrants and immigration: An instrumental model of group conflict. Journal of Social Issues, 54(4), 699-724. https://doi.org/10.1111/j.1540-4560.1998.tb01244.x

Federico, C. M., \& Sidanius, J. (2002). Racism, ideology, and affirmative action revisited: The antecedents and consequences of "principled objections" to affirmative action. Journal of Personality and Social Psychology, 82(4), 488-502. https://doi.org/10.1037/0022$\underline{3514.82 .4 .488}$

Fershtman, C., \& Gneezy, U. (2001). Discrimination in a segmented society: An experimental approach. The Quarterly Journal of Economics, 116(1), 351-377. https://doi.org/10.1162/003355301556338 
Festinger, L. (1954). A theory of social comparison processes. Human Relations, 7(2), 117-140. https://doi.org/10.1177/001872675400700202

Fingerhut, H. (2018, June 14). Most Americans express positive views of country's growing racial and ethnic diversity. Pew Research Center. https://www.pewresearch.org/fact$\operatorname{tank} / 2018 / 06 / 14 /$ most-americans-express-positive-views-of-countrys-growing-racial-andethnic-diversity/

Fiske, S. T., \& Neuberg, S. L. (1990). A continuum of impression formation, from categorybased to individuating processes: Influences of information and motivation on attention and interpretation. Advances in Experimental Social Psychology, 23, 1-74. https://doi.org/10.1016/S0065-2601(08)60317-2

Gershgorn, D. (2019, April 19). Microsoft staff are openly questioning the value of diversity. Quartz. https://qz.com/1598345/microsoft-staff-are-openly-questioning-the-value-ofdiversity/

Greenwald, A. G., \& Banaji, M. R. (1995). Implicit social cognition: Attitudes, self-esteem, and stereotypes. Psychological Review, 102(1), 4 -27. http://dx.doi.org/10.1037/0033$\underline{295 X .102 .1 .4}$

Gu, J., McFerran, B., Aquino, K., \& Kim, T. G. (2014). What makes affirmative action-based hiring decisions seem (un)fair? A test of an ideological explanation for fairness judgments. Journal of Organizational Behavior, 35(5), 722-745. https://doi.org/10.1002/job.1927

Guimond, S., Dambrun, M., Michinov, N., \& Duarte, S. (2003). Does social dominance generate prejudice? Integrating individual and contextual determinants of intergroup cognitions. 
Journal of Personality and Social Psychology, 84(4), 697-721. https://doi.org/10.1037/0022-3514.84.4.697

Gutiérrez, A. S., \& Unzueta, M. M. (2013). Are admissions decisions based on family ties fairer than those that consider race? Social dominance orientation and attitudes toward legacy vs. affirmative action policies. Journal of Experimental Social Psychology, 49(3), 554558. https://doi.org/10.1016/j.jesp.2012.10.011

Halevy, N., Chou, E. Y., Cohen, T. R., \& Bornstein, G. (2010). Relative deprivation and intergroup competition. Group Processes \& Intergroup Relations, 13(6), 685-700. https://doi.org/10.1177/1368430210371639

Harinck, F., De Dreu, C. K., \& Van Vianen, A. E. (2000). The impact of conflict issues on fixedpie perceptions, problem solving, and integrative outcomes in negotiation. Organizational Behavior and Human Decision Processes, 81(2), 329-358. https://doi.org/10.1006/obhd.2000.2909

Harrison, D. A., Kravitz, D. A., Mayer, D. M., Leslie, L. M., \& Lev-Arey, D. (2006). Understanding attitudes toward affirmative action programs in employment: Summary and meta-analysis of 35 years of research. Journal of Applied Psychology, 91(5), 10131036. https://doi.org/10.1037/0021-9010.91.5.1013

Hartocollis, A. (2020, August 14). Justice Dept. accuses Yale of discrimination in application process. The New York Times. https://www.nytimes.com/2020/08/13/us/yalediscrimination.html

Hastorf, A. H., \& Cantril, H. (1954). They saw a game: A case study. The Journal of Abnormal and Social Psychology, 49(1), 129-134. https://doi.org/10.1037/h0057880 
Hayes, A. F. (2012). PROCESS: A versatile computational tool for observed variable mediation, moderation, and conditional process modeling [White paper]. http://www.afhayes.com/public/ process2012.pdf

Hekman, D. R., Johnson, S. K., Foo, M. D., \& Yang, W. (2017). Does diversity-valuing behavior result in diminished performance ratings for non-white and female leaders? Academy of Management Journal, 60(2), 771-797. https://doi.org/10.5465/amj.2014.0538

Hideg, I., \& Ferris, D. L. (2017). Dialectical thinking and fairness-based perspectives of affirmative action. Journal of Applied Psychology, 102(5), 782-801. https://doi.org/10.1037/ap10000207

Ho, A. K., Sidanius, J., Kteily, N., Sheehy-Skeffington, J., Pratto, F., Henkel, K. E., Foels, R., \& Stewart, A. L. (2015). The nature of social dominance orientation: Theorizing and measuring preferences for intergroup inequality using the new $\mathrm{SDO}_{7}$ scale. Journal of Personality and Social Psychology, 109(6), 1003-1028. https://doi.org/10.1037/pspi0000033

Ho, G. C., \& Unzueta, M. M. (2015). Antiegalitarians for affirmative action? When social dominance orientation is positively related to support for egalitarian social policies. Journal of Applied Social Psychology, 45(8), 451-460. https://doi.org/10.1111/jasp.12311

Hofstra, B., Kulkarni, V. V., Galvez, S. M. N., He, B., Jurafsky, D., \& McFarland, D. A. (2020). The Diversity-Innovation paradox in science. Proceedings of the National Academy of Sciences, 117(17), 9284-9291. https://doi.org/10.1073/pnas.1915378117

Horowitz, J. M. (2019, May 8). Americans see advantages and challenges in country's growing racial and ethnic diversity. Pew Research Center. 
https://www.pewsocialtrends.org/2019/05/08/americans-see-advantages-and-challengesin-countrys-growing-racial-and-ethnic-diversity/

Hudson, S. K. T. J., Cikara, M., \& Sidanius, J. (2019). Preference for hierarchy is associated with reduced empathy and increased counter-empathy towards others, especially out-group targets. Journal of Experimental Social Psychology, 85, 1-12. https://doi.org/10.1016/j.jesp.2019.103871

Jackson, J. C., \& Payne, K. (2020). Cognitive barriers to reducing income inequality. Social Psychological and Personality Science, Advance online publication. https://doi.org/10.1177/1948550620934597

Jacoby-Senghor, D. S., Rosenblum, M., \& Brown, N. D. (2021). Not all egalitarianism is created equal: Claims of nonprejudice inadvertently communicate prejudice between ingroup members. Journal of Experimental Social Psychology, 94, 104104. https://doi.org/10.1016/j.jesp.2021.104104

James, E. H., Brief, A. P., Dietz, J., \& Cohen, R. R. (2001). Prejudice matters: Understanding the reactions of Whites to affirmative action programs targeted to benefit Blacks. Journal of Applied Psychology, 86(6), 1120-1128. https://doi.org/10.1037/0021-9010.86.6.1120

Johnson, S. G., Zhang, J., \& Keil, F. (2020). Win-win denial: The psychological underpinnings of zero-sum thinking. PsyArXiv. https://10.31234/osf.io/efs5y

Jones, K. S., Anantharaman, A., \& Bhatt, A. (2019). Framing matters: The influence of groupimage threat on reactions to affirmative action policies. Personnel Assessment and Decisions, 5(2), 73-81. https://doi.org/10.25035/pad.2019.02.009

Jost, J. T., Banaji, M. R., \& Nosek, B. A. (2004). A decade of system justification theory: Accumulated evidence of conscious and unconscious bolstering of the status 
quo. Political Psychology, 25(6), 881-919. https://doi.org/10.1111/j.1467$\underline{9221.2004 .00402 . x}$

Kay, A. C., \& Brandt, M. J. (2016). Ideology and intergroup inequality: Emerging directions and trends. Current Opinion in Psychology, 11, 110-114. https://doi.org/10.1016/j.copsyc.2016.07.007

Kay, A. C., \& Jost, J. T. (2003). Complementary justice: Effects of "Poor but Happy" and "Poor but Honest" stereotype exemplars on system justification and implicit activation of the justice motive. Journal of Personality and Social Psychology, 85(5), 823-837. https://doi.org/10.1037/0022-3514.85.5.823

Kehn, A., \& Ruthig, J.C. (2013). Perceptions of gender discrimination across six decades: The moderating roles of gender and age. Sex Roles, 69, 289-296. http://dx.doi.org/10.1007/s11199-013-0303-2.

Kern, M. C., Brett, J. M., Weingart, L. R., \& Eck, C. S. (2020). The "fixed" pie perception and strategy in dyadic versus multiparty negotiations. Organizational Behavior and Human Decision Processes, 157, 143-158. https://doi.org/10.1016/j.obhdp.2020.01.001

King, M. L. Jr. (1963). Letter from Birmingham jail. The Martin Luther King, Jr. Research and Education Institute, Stanford University, Stanford, CA, United States. http://okra.stanford.edu/transcription/document_images/undecided/630416-019.pdf

Knowles, E. D., Lowery, B. S., Hogan, C. M., \& Chow, R. M. (2009). On the malleability of ideology: Motivated construals of color blindness. Journal of Personality and Social Psychology, 96(4), 857-869. https://doi.org/10.1037/a0013595 
Kramer, M. (2019, March 30). A timeline of key Supreme Court cases on affirmative action. The New York Times. https://www.nytimes.com/2019/03/30/us/affirmative-action-supremecourt.html

Kraus, M. W., Onyeador, I. N., Daumeyer, N. M., Rucker, J. M., \& Richeson, J. A. (2019). The misperception of racial economic inequality. Perspectives on Psychological Science, 14(6), 899-921. https://doi.org/10.1177/1745691619863049

Kraus, M. W., Rucker, J. M., \& Richeson, J. A. (2017). Americans misperceive racial economic equality. Proceedings of the National Academy of Sciences, 114(39), 10324-10331. https://doi.org/10.1073/pnas.1707719114

Kteily, N. S., \& Richeson, J. A. (2016). Perceiving the world through hierarchy-shaped glasses: On the need to embed social identity effects on perception within the broader context of intergroup hierarchy. Psychological Inquiry, 27(4), 327-334. https://doi.org/10.1080/1047840X.2016.1215212

Kteily, N. S., Sidanius, J., \& Levin, S. (2011). Social dominance orientation: Cause or 'mere effect'?: Evidence for SDO as a causal predictor of prejudice and discrimination against ethnic and racial outgroups. Journal of Experimental Social Psychology, 47(1), 208-214. https://doi.org/10.1016/j.jesp.2010.09.009

Kteily, N. S., Sheehy-Skeffington, J., \& Ho, A. K. (2017). Hierarchy in the eye of the beholder: (Anti-)egalitarianism shapes perceived levels of social inequality. Journal of Personality and Social Psychology, 112(1), 136-159. https://doi.org/10.1037/pspp0000097

Kunstman, J. W., Tuscherer, T., Trawalter, S., \& Lloyd, E. P. (2016). What lies beneath? Minority group members' suspicion of Whites' egalitarian motivation predicts responses 
to Whites' smiles. Personality and Social Psychology Bulletin, 42(9), 1193-1205. https://doi.org/10.1177/0146167216652860

Leach, C. W., Snider, N., \& Iyer, A. (2002). "Poisoning the consciences of the fortunate": The experience of relative advantage and support for social equality. In I. Walker \& H. J. Smith (Eds.), Relative deprivation: Specification, development, and integration (p. 136163). Cambridge University Press.

Leslie, L. M. (2019). Diversity initiative effectiveness: A typological theory of unintended consequences. Academy of Management Review, 44(3), 538-563. https://doi.org/10.5465/amr.2017.0087

Levin, S. (1996). A social psychological approach to understanding intergroup attitudes in the United States and Israel. [Unpublished doctoral dissertation]. UCLA.

Levine, S. S., Apfelbaum, E. P., Bernard, M., Bartelt, V. L., Zajac, E. J., \& Stark, D. (2014). Ethnic diversity deflates price bubbles. Proceedings of the National Academy of Sciences, 111(52), 18524-18529. https://doi.org/10.1073/pnas.1407301111

Lowery, B. S., Chow, R. M., Knowles, E. D., \& Unzueta, M. M. (2012). Paying for positive group esteem: How inequity frames affect whites' responses to redistributive policies. Journal of Personality and Social Psychology, 102(2), 323336. https://doi.org/10.1037/a0024598

Lowery, B. S., Knowles, E. D., \& Unzueta, M. M. (2007). Framing inequity safely: Whites' motivated perceptions of racial privilege. Personality and Social Psychology Bulletin, 33(9), 1237-1250. https://doi.org/10.1177/0146167207303016 
Lowery, B. S., Unzueta, M. M., Knowles, E. D., \& Goff, P. A. (2006). Concern for the in-group and opposition to affirmative action. Journal of Personality and Social Psychology, 90(6), 961-974. https://doi.org/10.1037/0022-3514.90.6.961

Luhtanen, R., \& Crocker, J. (1992). A collective self-esteem scale: Self-evaluation of one's social identity. Personality and Social Psychology Bulletin, 18(3), 302-318. https://doi.org/10.1177/0146167292183006

Major, B., \& Kaiser, C. R. (2017). Ideology and the maintenance of group inequality. Group Processes \& Intergroup Relations, 20(5), 582-592. https://doi.org/10.1177/1368430217712051

Marques, J. (2008). Workplace diversity: Developing a win-win-win strategy. Development and Learning in Organizations, 22(5), 5-8. https://doi.org/10.1108/14777280810896372

McConahay, J. B. (1986). Modern racism, ambivalence, and the Modern Racism Scale. In J. F. Dovidio \& S. L. Gaertner (Eds.), Prejudice, discrimination, and racism (p. 91-125). Academic Press.

Meegan, D. V. (2010). Zero-sum bias: Perceived competition despite unlimited resources. Frontiers in Psychology, 1, 1-7. https://doi.org/10.3389/fpsyg.2010.00191

Mendes, W. B., \& Koslov, K. (2013). Brittle smiles: Positive biases toward stigmatized and outgroup targets. Journal of Experimental Psychology: General, 142(3), 923-933. https://doi.org/10.1037/a0029663

Minkin, R. (2020, July 14). Most Americans support gender equality, even if they don't identify as feminists. Pew Research Center. https://www.pewresearch.org/fact$\underline{\operatorname{tank} / 2020 / 07 / 14 / \text { most-americans-support-gender-equality-even-if-they-dont-identify-as- }}$ feminists/ 
Molnar, A., Renahy, E., O’Campo, P., Muntaner, C., Freiler, A., \& Shankardass, K. (2016). Using win-win strategies to implement health in all policies: A cross-case analysis. PloS One, 11(2), e0147003. https://doi.org/10.1371/journal.pone.0147003

Morris, A. (2020, August 3). We'll never fix systemic racism by being polite. Scientific American. https://www.scientificamerican.com/article/well-never-fix-systemic-racismby-being-polite/

Morrison, K. R., Plaut, V. C., \& Ybarra, O. (2010). Predicting whether multiculturalism positively or negatively influences white Americans' intergroup attitudes: The role of ethnic identification. Personality and Social Psychology Bulletin, 36(12), 1648-1661. https://doi.org/10.1177/0146167210386118

Moscatelli, S., Albarello, F., Prati, F., \& Rubini, M. (2014). Badly off or better off than them? The impact of relative deprivation and relative gratification on intergroup discrimination. Journal of Personality and Social Psychology, 107(2), 248264. https://doi.org/10.1037/a0036704

Nishii, L. H., Khattab, J., Shemla, M., \& Paluch, R. M. (2018). A multi-level process model for understanding diversity practice effectiveness. Academy of Management Annals, 12(1), 37-82. https://doi.org/10.5465/annals.2016.0044

Norton, M. I., \& Sommers, S. R. (2011). Whites see racism as a zero-sum game that they are now losing. Perspectives on Psychological Science, 6(3), 215-218. https://doi.org/10.1177/1745691611406922

Onyeador, I. N., Daumeyer, N. M., Rucker, J. M., Duker, A., Kraus, M. W., \& Richeson, J. A. (2020). Disrupting beliefs in racial progress: Reminders of persistent racism alter perceptions of past, but not current, racial economic equality. Personality and Social 
Psychology Bulletin. Advance online publication. https://doi.org/10.1177/0146167220942625

Outten, H. R., Schmitt, M. T., Miller, D. A., \& Garcia, A. L. (2012). Feeling threatened about the future: Whites' emotional reactions to anticipated ethnic demographic changes. Personality and Social Psychology Bulletin, 38(1), 14-25. https://doi.org/10.1177/0146167211418531

Parker, K., Horowitz, J. M., \& Anderson, M. (2020, June 12). Amid Protests, Majorities Across Racial and Ethnic Groups Express Support for the Black Lives Matter Movement. Pew Research Center. https://www.pewsocialtrends.org/2020/06/12/amid-protests-majoritiesacross-racial-and-ethnic-groups-express-support-for-the-black-lives-matter-movement/

Parsons, T. (1951). The social system. Free Press.

Perdue, C. W., Dovidio, J. F., Gurtman, M. B., \& Tyler, R. B. (1990). Us and them: Social categorization and the process of intergroup bias. Journal of Personality and Social Psychology, 59(3), 475-486. https://doi.org/10.1037/0022-3514.59.3.475

Plaut, V. C. (2011). Law and the zero-sum game of discrimination: Commentary on Norton and Sommers (2011). Perspectives on Psychological Science, 6(3), 219-221. https://doi.org/10.1177/1745691611406929

Plaut, V. C., Garnett, F. G., Buffardi, L. E., \& Sanchez-Burks, J. (2011). "What about me?" Perceptions of exclusion and whites' reactions to multiculturalism. Journal of Personality and Social Psychology, 101(2), 337-353. https://doi.org/10.1037/a0022832

Phillips, L. T., \& Lowery, B. S. (2015). The hard-knock life? Whites claim hardships in response to racial inequity. Journal of Experimental Social Psychology, 61, 12-18. https://doi.org/10.1016/j.jesp.2015.06.008 
Phillips, L. T., \& Lowery, B. S. (2020). I ain't no fortunate one: On the motivated denial of class privilege. Journal of Personality and Social Psychology, 119(6), 1403-1422. https://doi.org/10.1037/pspi0000240

Phillips, K. W. (2014, October 1). How diversity makes us smarter. Scientific American. https://www.scientificamerican.com/article/how-diversity-makes-us-smarter/

Phillips, K. W., \& Loyd, D. L. (2006). When surface and deep-level diversity collide: The effects on dissenting group members. Organizational Behavior and Human Decision Processes, 99(2), 143-160. https://doi.org/10.1016/j.obhdp.2005.12.001

Phillips, K. W., Northcraft, G. B., \& Neale, M. A. (2006). Surface-level diversity and decisionmaking in groups: When does deep-level similarity help?. Group Processes \& Intergroup Relations, 9(4), 467-482. https://doi.org/10.1177/1368430206067557

Pinkley, R. L., Griffith, T. L., \& Northcraft, G. B. (1995). "Fixed pie” a la mode: Information availability, information processing, and the negotiation of suboptimal agreements. Organizational Behavior and Human Decision Processes, 62(1), 101-112. https://doi.org/10.1006/obhd.1995.1035

Ponce de Leon, R., Wingrove, S., \& Kay, A. C. (2020). Scientific skepticism and inequality: Political and ideological roots. Journal of Experimental Social Psychology, 91, 104045. https://doi.org/10.1016/j.jesp.2020.104045

Pratto, F., Sidanius, J., Stallworth, L. M., \& Malle, B. F. (1994). Social dominance orientation: A personality variable predicting social and political attitudes. Journal of Personality and Social Psychology, 67(4), 741-763. https://doi.org/10.1037/0022-3514.67.4.741 
Rabelo, V. C., Robotham, K. J., \& McCluney, C. L. (2020). “Against a sharp white background": How Black women experience the white gaze at work. Gender, Work \& Organization. Advance online publication. https://doi.org/10.1111/gwao.12564

Rattan, A., \& Ambady, N. (2013). Diversity ideologies and intergroup relations: An examination of colorblindness and multiculturalism. European Journal of Social Psychology, 43(1), 12-21. https://doi.org/10.1002/ejsp.1892

Ray, V. (2019). A theory of racialized organizations. American Sociological Review, 84(1), 2653. https://doi.org/10.1177/0003122418822335

Reeves, R. V. (2018). Dream hoarders: How the American upper middle class is leaving everyone else in the dust, why that is a problem, and what to do about it. Brookings Institution Press.

Regents of the University of California v. Bakke, 438 U.S. 265 (1978).

Richeson, J. A., \& Sommers, S. R. (2016). Toward a social psychology of race and race relations for the twenty-first century. Annual Review of Psychology, 67, 439-463. https://doi.org/10.1146/annurev-psych-010213-115115

Rosenblum, M., Jacoby-Senghor, D. S., \& Brown, N. D. (2021). It's not what you said, it's how you said it: Blacks' perceptions of white egalitarianism. [Manuscript submitted for publication].

Rothenberg, J. (2018, June 07). Championing diversity without discriminating: An employer's dilemma. Troutman Pepper. https://www.troutman.com/insights/championing-diversity$\underline{\text { without-discriminating-an-employers-dilemma.html }}$ 
Różycka-Tran, J., Boski, P., \& Wojciszke, B. (2015). Belief in a zero-sum game as a social axiom: A 37-nation study. Journal of Cross-Cultural Psychology, 46(4), 525-548. https://doi.org/10.1177/0022022115572226

Shteynberg, G., Leslie, L. M., Knight, A. P., \& Mayer, D. M. (2011). But affirmative action hurts us! Race-related beliefs shape perceptions of white disadvantage and policy unfairness. Organizational Behavior and Human Decision Processes, 115(1), 1-12. https://doi.org/10.1016/j.obhdp.2010.11.011

Sidanius, J., \& Pratto, F. (2001). Social dominance: An intergroup theory of social hierarchy and oppression. Cambridge University Press.

Sidanius, J., Pratto, F., \& Mitchell, M. (1994). In-group identification, social dominance orientation, and differential intergroup social allocation. The Journal of Social Psychology, 134(2), 151-167. https://doi.org/10.1080/00224545.1994.9711378

Sirola, N., \& Pitesa, M. (2017). Economic downturns undermine workplace helping by promoting a zero-sum construal of success. Academy of Management Journal, 60(4), 1339-1359. https://doi.org/10.5465/amj.2015.0804

Smith, H. J., Pettigrew, T. F., Pippin, G. M., \& Bialosiewicz, S. (2012). Relative deprivation: A theoretical and meta-analytic review. Personality and Social Psychology Review, 16(3), 203-232. https://doi.org/10.1177/1088868311430825

Sullivan, S. (2014). Good white people: The problem with middle-class white anti-racism. State University of New York Press.

Tajfel, H. (1970). Experiments in intergroup discrimination. Scientific American, 223(5), 96-103. 
Tajfel, H., Billig, M. G., Bundy, R. P., \& Flament, C. (1971). Social categorization and intergroup behaviour. European Journal of Social Psychology, 1(2), 149-178. https://doi.org/10.1002/ejsp.2420010202

Tajfel, H., \& Turner, J. C. (1979). An integrative theory of intergroup conflict. In W. Austin \& S. Worchel (Eds.), The social psychology of intergroup relations (pp. 33-47). Brooks/Cole.

Thompson, L., \& Hastie, R. (1990). Social perception in negotiation. Organizational Behavior and Human Decision Processes, 47(1), 98-123. https://doi.org/10.1016/0749$\underline{5978(90) 90048-\mathrm{E}}$

Turner, J. C., Hogg, M.A., Oakes, P. J., Reicher, S. D., \& Wetherell, M. S. (1987). Rediscovering the social group: A self-categorization theory. Basil Blackwell.

Unzueta, M. M., \& Binning, K. R. (2012). Diversity is in the eye of the beholder: How concern for the in-group affects perceptions of racial diversity. Personality and Social Psychology Bulletin, 38(1), 26-38. https://doi.org/10.1177/0146167211418528

Unzueta, M. M., \& Lowery, B. S. (2008). Defining racism safely: The role of self-image maintenance on white Americans' conceptions of racism. Journal of Experimental Social Psychology, 44(6), 1491-1497. https://doi.org/10.1016/j.jesp.2008.07.011

Unzueta, M. M., Lowery, B. S., \& Knowles, E. D. (2008). How believing in affirmative action quotas protects White men's self-esteem. Organizational Behavior and Human Decision Processes, 105(1), 1-13. https://doi.org/10.1016/j.obhdp.2007.05.001

U.S. Census Bureau (2020). QuickFacts_California; United States. https://www.census.gov/quickfacts/fact/table/CA,US/PST045219 
Verkuyten, M. (2005). Ethnic group identification and group evaluation among minority and majority groups: Testing the multiculturalism hypothesis. Journal of Personality and Social Psychology, 88(1), 121-138. https://doi.org/10.1037/0022-3514.88.1.121

Wakabayashi, D. (2017, August 8). Contentious memo strikes nerve inside Google and out. The New York Times. https://www.nytimes.com/2017/08/08/technology/google-engineerfired-gender-memo.html

Walker, H. J., Feild, H. S., Giles, W. F., Bernerth, J. B., \& Jones-Farmer, L. A. (2007). An assessment of attraction toward affirmative action organizations: Investigating the role of individual differences. Journal of Organizational Behavior, 28(4), 485-507. https://doi.org/10.1002/job.434

Wetherell, G. A., Brandt, M. J., \& Reyna, C. (2013). Discrimination across the ideological divide: The role of value violations and abstract values in discrimination by liberals and conservatives. Social Psychological and Personality Science, 4(6), 658-667. https://doi.org/10.1177/1948550613476096

Wilkins, C. L., \& Kaiser, C. R. (2014). Racial progress as threat to the status hierarchy: Implications for perceptions of anti-white bias. Psychological Science, 25(2), 439-446. https://doi.org/10.1177/0956797613508412

Wilkins, C. L., Wellman, J. D., Babbitt, L. G., Toosi, N. R., \& Schad, K. D. (2015). You can win but I can't lose: Bias against high-status groups increases their zero-sum beliefs about discrimination. Journal of Experimental Social Psychology, 57, 1-14. https://doi.org/10.1016/j.jesp.2014.10.008

Wolsko, C., Park, B., \& Judd, C. M. (2006). Considering the tower of Babel: Correlates of assimilation and multiculturalism among ethnic minority and majority groups in the 
United States. Social Justice Research, 19(3), 277-306. https://doi.org/10.1007/s11211$\underline{006-0014-8}$

Xiao, Y. J., Coppin, G., \& Van Bavel, J. J. (2016). Perceiving the world through group-colored glasses: A perceptual model of intergroup relations. Psychological Inquiry, 27(4), 255274. https://doi.org/10.1080/1047840X.2016.1199221

Xiao, Y. J., \& Van Bavel, J. J. (2012). See your friends close and your enemies closer: Social identity and identity threat shape the representation of physical distance. Personality and Social Psychology Bulletin, 38(7), 959-972. https://doi.org/10.1177/0146167212442228 